DIW BERLIN

Discussion

Papers
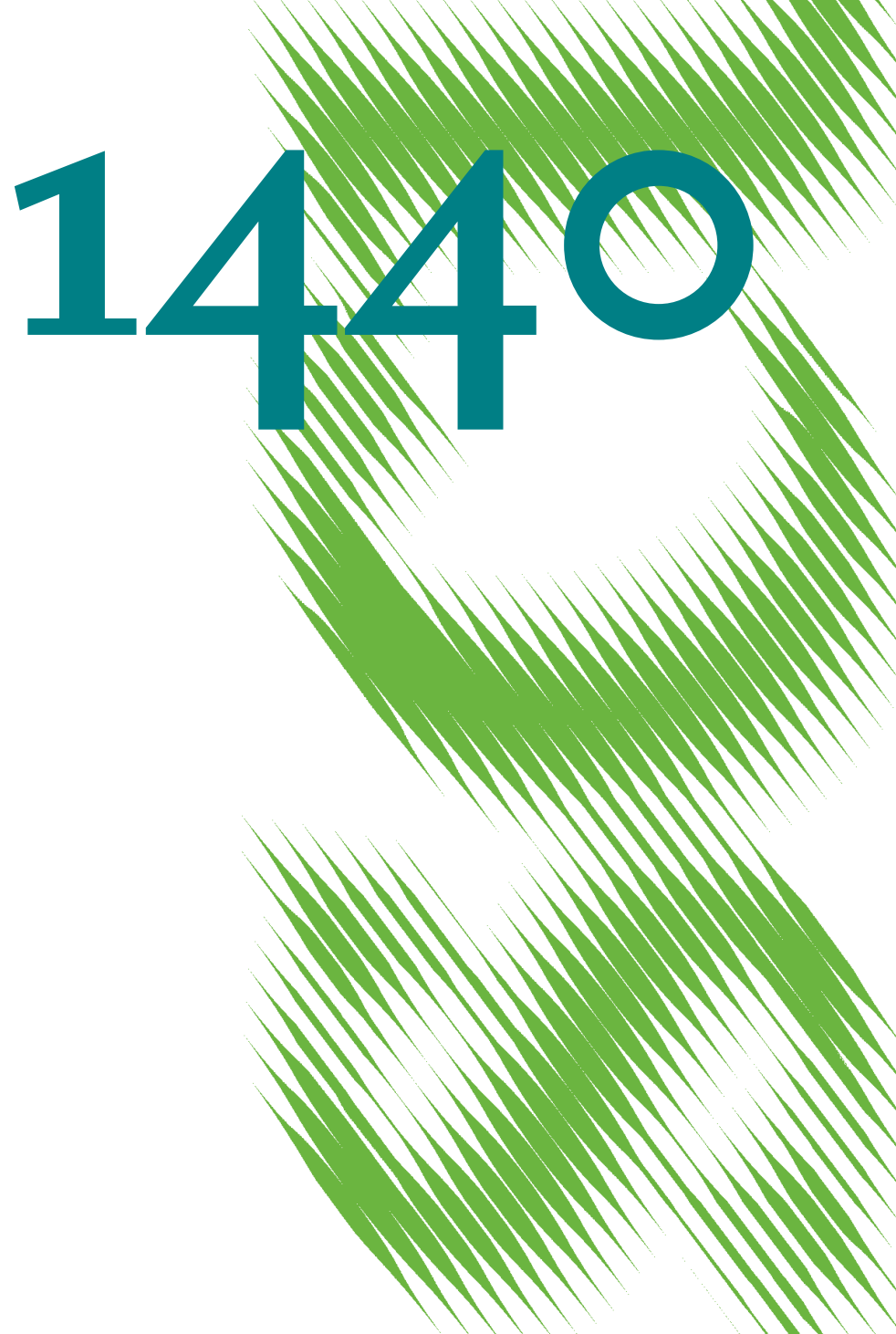

Collusive Effects of a Monopolist's Use of an Intermediary to Deliver to Retailers 
Opinions expressed in this paper are those of the author(s) and do not necessarily reflect views of the institute.

IMPRESSUM

(C) DIW Berlin, 2014

DIW Berlin

German Institute for Economic Research

Mohrenstr. 58

10117 Berlin

Tel. +49 (30) $89789-0$

Fax +49 (30) $89789-200$

http://www.diw.de

ISSN electronic edition 1619-4535

Papers can be downloaded free of charge from the DIW Berlin website:

http://www.diw.de/discussionpapers

Discussion Papers of DIW Berlin are indexed in RePEc and SSRN:

http://ideas.repec.org/s/diw/diwwpp.html

http://www.ssrn.com/link/DIW-Berlin-German-Inst-Econ-Res.html 


\title{
Collusive effects of a monopolist's use of an intermediary to deliver to retailers*
}

\author{
Isabel Teichmann ${ }^{\dagger} \quad$ Vanessa von Schlippenbach ${ }^{\ddagger}$
}

December 2014

\begin{abstract}
A manufacturer contracting secretly with several downstream competitors faces an opportunism problem, preventing it from exerting its market power. In an infinitely repeated game, the opportunism problem can be relaxed. We show that the upstream firm's market power can be restored even further if the upstream firm chooses a mixed distribution system in which it makes use of an intermediary to distribute the good to a subset of the retailers and delivers directly only to the remaining downstream firms.
\end{abstract}

JEL Classification: L12, L14, L42

Keywords: Vertical relations, Delegation, Downstream Monopolization, Commitment problem, Channel structure, Multi-tier industry

*We thank Pio Baake, Stéphane Caprice, Andreas Harasser and Massimo Motta as well as participants of the IEA world congress (Dead Sea, Jordan, 2014), the EARIE congress (Évora, 2013), the EEA congress (Gothenburg, 2013), the workshop "Market Power in Vertically Related Markets" (Toulouse, 2012) and seminar participants at DIW Berlin, Humboldt-Universität zu Berlin and DICE Düsseldorf for their helpful comments and suggestions. Both authors gratefully acknowledge financial support from the Deutsche Forschungsgemeinschaft (FOR 986).

${ }^{\dagger}$ Deutsches Institut für Wirtschaftsforschung (DIW) Berlin and Humboldt-Universität zu Berlin, e-mail: iteichmann@diw.de

${ }^{\ddagger}$ Corresponding author. Deutsches Institut für Wirtschaftsforschung (DIW) Berlin and Universität Düsseldorf, Düsseldorf Institute for Competition Economics (DICE), e-mail: vschlippenbach@diw.de 


\section{Introduction}

Most commonly, manufacturers of consumer goods sell their products to retailers for further distribution to consumers. ${ }^{1}$ Thereby, they can either sell their products directly to the retailers or make use of an intermediary, such as a distributor or a wholesaler. In some countries (e.g., Norway, Sweden, and Brazil), the Coca-Cola Company, for example, sells its soft-drink concentrates and syrups to independent bottlers, which first produce and then sell the final beverages to the local retailers. In other countries (e.g., the United States, Canada, and Germany), however, it makes use of company-owned bottling operations and, thus, sells the consumer-ready beverages directly to the retailers. ${ }^{2}$ While the Coca-Cola Company-depending on its respective country strategy - is either directly or indirectly linked to the local retailers, other manufacturers use a combination of both distribution channels to reach final consumers in the same local market (multi-channel distribution). A prominent example is Apple, which switched from exclusive distribution of its products through telecommunications companies to a multi-channel distribution strategy. In Germany, for example, Apple first distributed the iPhone directly and exclusively through T-Mobile and, since 2010, also through the mobile-service providers vodafone and o2. A few years later, Apple added an indirect link by authorizing three wholesalers (Ingram Micro and Tech Data in 2013 and Brodos in 2014) to sell the iPhone to local retailers for further distribution to final consumers. ${ }^{3}$

So far, the economic literature has motivated the use of intermediaries mainly by efficiency reasons resulting from the intermediaries' specialization and market knowledge (Rosenbloom 2013). ${ }^{4}$ However, efficiency reasons fall short in thoroughly explaining the existence of multichannel distribution structures. Building on a strategic effect, this paper provides a new rationale for a manufacturer's decision to supply some retailers directly and others indirectly via an intermediary. We show that the coexistence of the direct and indirect distribution to retailers enables the manufacturer to keep downstream prices high and, thus, facilitates vertical collusion whenever the intermediary has some bargaining power vis-à-vis the manufacturer, the interme-

\footnotetext{
${ }^{1}$ This is true for almost all consumer goods, such as groceries, drugs and electronics. Recently, however, many manufacturers have added direct online channels to their existing offline retail networks. That is, they also sell their products directly to the final consumers. Strategic reasons for a manufacturer to implement a direct (online) sales channel alongside an indirect retail channel are analyzed by Chiang et al. (2003), Tsay and Agrawal (2004) as well as Hsiao and Chen (2014), for example.

${ }^{2}$ See http://www.coca-colacompany.com/our-company/the-coca-cola-system (accessed on 16 September 2014).

${ }^{3}$ Similarily, the Lotus Development Corporation (before its acquisition by IBM in 1995) supplied the retailers both directly and indirectly through intermediaries. Until 1984, it had distributed its products to computer retailers only through software wholesalers. Some of these computer retailers sold large volumes, which made them eligible for remarkable quantity discounts of $35 \%$ to $40 \%$ when buying directly from Lotus. Correspondingly, some of these large retailers approached Lotus for direct shipments; and, in August 1984, Lotus altered its distribution strategy by delivering directly to its 30 largest retail dealers. The company's five wholesalers, however, still served the rest of the retail market (see Rangan and Jaikumar 1991).

${ }^{4}$ Additionally, intermediaries are seen as a means to enhance the contactual efficiency for the manufacturer by reducing the number of sales visits or phone calls necessary to sell the good (Rosenbloom 2013: 20-22).
} 
diary is more efficient in distributing to the retailers than the manufacturer, and the delivery to the retailers is sufficiently costly.

We consider a vertically related industry with an upstream firm and a finite number of differentiated downstream firms. The firms engage in an infinitely repeated game. Ex-ante, the upstream firm decides whether to distribute its product directly to the downstream firms (integrated distribution), to delegate the distribution to an intermediate firm which then delivers to the retailers (disintegrated distribution), or to use a combination of both distribution channels (mixed distribution). The firm(s) dealing with the retailers - either the manufacturer or the intermediary or both - incur(s) fixed distribution costs, whereby the intermediary may have a competitive advantage in distribution. In each stage game, the upstream firm-when having chosen the disintegrated or mixed distribution system - negotiates with the intermediary about a complex contract including an upfront payment to be made by the intermediary upon successful negotiations (e.g., a license or franchise fee) and a conditional fee to be paid by the intermediary if it actually buys a predetermined quantity (cf. Marx and Shaffer 2007; Miklós-Thal et al. 2011). Then, the intermediate firm and possibly the upstream firm make simultaneous and secret take-it-or-leave-it offers about quantity-forcing contracts to their respective downstream firms. Under integrated distribution, each stage game starts with the upstream firm's takeit-or-leave-it offers to the downstream firms. When deciding about accepting or rejecting the contract offers, the retailers hold passive beliefs (i.e. market-by-market conjectures). That is, when receiving an unexpected (or out-of-equilibrium) offer, they believe that the rival retailers are still offered the equilibrium contract. Consistently with the retailers' beliefs, the upstream firm and the intermediary also hold passive beliefs when negotiating with each other.

Under secret non-linear delivery tariffs, a monopolistic manufacturer selling to a number of retailers is usually not able to exert its market power. The reason is that it cannot credibly commit to supply contracts that induce the maximization of the overall industry profit-i.e. supply contracts with input prices above marginal cost or low quantities (Hart and Tirole 1990; O'Brien and Shaffer 1992; McAfee and Schwartz 1994). Suppose that one downstream competitor has accepted a take-it-or-leave-it contract consistent with the integrated monopoly outcome. Then, the upstream firm has an incentive to offer the rival downstream firms a lower price or larger quantity, imposing a loss on the former downstream firm. This opportunistic behavior is anticipated by the downstream firms, such that the upstream monopolist cannot leverage its market power downstream and extract the respective monopoly rents. However, the supplier's market power can be fully restored by the vertical integration of the supplier with one of the retailers combined with the foreclosure of the rival downstream firms (Hart and Tirole 1990), the use of exclusive-dealing contracts or exclusive territories (Rey and Tirole 2007; McAfee and Schwartz 1994), resale-price maintenance (e.g., in the form of industry-wide price floors) (O'Brien and Shaffer 1992), bilateral buyback contracts with or without individual price ceil- 
ings (Montez 2014), as well as non-discrimination clauses in the sense of most-favored-customer clauses (DeGraba and Postlewaite 1992; DeGraba 1996; Marx and Shaffer 2004). ${ }^{5}$ Furthermore, the upstream firm's commitment problem can be relaxed in dynamic settings (Hardt 1995). Considering an infinitely repeated game, we show that the upstream firm's choice of the distribution system has an impact on the sustainability of vertical collusion. In particular, we find that the commitment problem is less severe when the upstream firm makes use of an intermediary.

In comparison to the integrated distribution, the use of an intermediary in a mixed distribution system results in a smaller number of retailers directly supplied by the manufacturer and, thus, reduces the manufacturer's incentive to deviate from the collusive equilibrium path. This holds as long as the manufacturer has no incentive to cheat the intermediary by directly delivering to the retailers initially assigned to the intermediate firm. The manufacturer can commit to the mixed distribution structure by agreeing with the intermediary on a complex contract consisting of an upfront payment and a conditional fee to be paid by the intermediary if it actually buys a fixed quantity. ${ }^{6}$ In addition to its individual deviation incentive, the upstream firm could also have an incentive to deviate jointly with the intermediary. However, joint deviation can only take place if both firms have an incentive to do so. We find that the intermediary's incentive constraint is always more binding than the upstream firm's if the intermediary has some bargaining power in the negotiations with the manufacturer. Quite intuitively, the intermediary's profit from joint deviation increases in the number of retailers it supplies. The intermediary's joint-deviation incentive is, therefore, lower under mixed distribution than under disintegrated distribution. Thus, our results reveal that the use of an intermediary in a mixed distribution system can reduce intra-brand competition. ${ }^{7}$ As the manufacturer has to share the profit with the intermediary, it is the more likely to implement a mixed distribution system the greater its bargaining power vis-à-vis the intermediary and the higher the efficiency of the intermediary in distributing the good. This implies that the choice of a more efficient intermediary may have tremendous anti-competitive effects.

Our findings contribute to the literature on collusion in vertically related industries. So far, this literature has mainly focused on horizontal collusion in infinitely repeated games of interbrand competition. A first strand of this literature deals with collusion between upstream firms. Jullien and Rey (2007), for example, provide conditions under which upstream collusion can be facilitated by resale-price maintenance when supply contracts are secret and final demand

\footnotetext{
${ }^{5}$ Considering ex-ante capital investments that determine the supplier's marginal costs of production, Baake et al. (2004) further show that a supplier's capital underinvestment partly restores the monopoly outcome.

${ }^{6}$ Assuming that the exclusive distribution network granted to the intermediary (and the upstream firm) is enforceable or that the re-organization of the distribution structure is sufficiently costly, our results also hold under simple quantity-forcing or two-part-tariff contracts.

${ }^{7}$ So far, the literature on strategic delegation (e.g., Vickers 1985; Bonanno and Vickers 1988; Rey and Stiglitz 1988, 1995; Piccolo and Reisinger 2011) has focused on inter-brand competition. That is, by using appropriate vertical restraints, manufacturers can instrument their retailers to credibly restrict inter-brand competition.
} 
is stochastic. Nocke and White $(2007 ; 2010)$, in turn, show that vertical integration of one (or more) supplier-buyer pair(s) facilitates upstream collusion when supply contracts are public and take the form of two-part tariffs. Normann (2009) finds that the same holds for linear input prices. Further, Piccolo and Reisinger (2011) illustrate that the elimination of intra-brand competition by the granting of exclusive territories by all competing upstream firms facilitates upstream collusion in inter-brand competition when supply contracts become observable. For public contracts, Schinkel et al. (2008) derive the result that low input prices offered to downstream firms in combination with vertical rationing of supplies can sustain upstream collusion when antitrust damage claims are legally restricted to direct purchasers. Another strand of the literature deals with collusion between downstream firms when they are supplied by upstream firms. In particular, Piccolo and Miklós-Thal (2012) show that collusion between downstream firms on input supply contracts in the form of wholesale prices above marginal costs combined with slotting fees facilitates downstream collusion on retail prices when the downstream firms have buyer power and when supply contracts become observable.

Our analysis differs in several respects: First, with the exception of Jullien and Rey (2007), ${ }^{8}$ the collusion literature tends to rely on public supply contracts or those that become observable or are credibly disclosed. By contrast, we do not require the assumption of observability or credible communication, but show how collusion can be sustained when input tariffs along the entire supply chain remain secret throughout. Further, aspects of vertical collusion have hardly been covered in the literature. The model by Schinkel et al. (2008) involves vertical collusion in so far as the downstream firms (i.e. the direct purchasers) benefit from upstream collusion due to the low input prices and, thus, do not sue the upstream cartel for antitrust damages. Moreover, in their web appendix, Nocke and White (2007) deal with vertical collusion when analyzing optimal punishment. Finally, our explicit focus on mixed distribution systems in intra-brand competition is novel. While Nocke and White (2007; 2010) and Normann (2009) can be viewed as involving a multi-channel distribution structure when the integrated upstream firm also delivers to unintegrated downstream firms, this structure is not driving the results. What matters in their models of inter-brand competition is that an upstream firm integrates with a firm selling to final consumers. To summarize, to the best of our knowledge, we are the first to focus on vertical collusion in an infinitely repeated game of intra-brand competition when supply contracts are not observable and when the distribution system is the deliberate choice of the upstream firm.

The remainder of the paper is organized as follows. In Section 2, we present our model. Section 3 contains the equilibrium analysis for all the given distribution systems, i.e. for integrated, disintegrated and mixed distribution. The optimal choice of the distribution system by

\footnotetext{
${ }^{8}$ Moreover, Nocke and White (2007) provide a robustness check of their findings for secret contract offers by the upstream firms in their web appendix.
} 
the upstream firm, in turn, is analyzed in Section 4. Finally, we conclude.

\section{The Model}

Consider an industry with an upstream firm $U$ (e.g., a manufacturer) that produces a homogenous input at constant marginal costs $c>0$ and $n \geq 2$ symmetrically differentiated downstream firms (e.g., retailers) which transform the input on a one-to-one basis into a final consumer good. The retailers' production and distribution costs are normalized to zero. The upstream firm either delivers directly to the downstream firms or delegates all or part of the delivery to an intermediate firm $M$ (e.g., a wholesaler). For the delivery to each retailer, the manufacturer incurs a fixed cost $K$ sufficiently high. ${ }^{9}$ The intermediary $M$, in turn, bears a fixed delivery cost $\alpha K$ with $\alpha \in(0,1)$, reflecting its cost advantage in delivering to the retailers compared to the manufacturer.

Let denote the retailers by $D_{i j}$ with $i \in\{U, M\}$ and $j \in\{1, \ldots, n\}$, whereby $i$ can be either $U$ or $M$ for any given $j$. Without loss of generality, we assume that the upstream manufacturer $U$ delivers directly to $m \in\{0, \ldots, n\}$ retailers, $D_{U 1}, \ldots, D_{U m}$, while the remaining $n-m$ retailers, $D_{M m+1}, \ldots, D_{M n}$, are supplied by the intermediary $M .{ }^{10}$ For $m=n$, the manufacturer makes direct deliveries to all retailers (integrated distribution), while all retailers are supplied by the intermediary for $m=0$ (disintegrated distribution). For $m \in(0, n)$, the systems of integrated and disintegrated distribution coexist (mixed distribution).

We consider an infinitely repeated game with discrete time $t \in\{1, . ., \infty\}$. Ex-ante, in period 0 , the manufacturer determines the distribution system. That is, the manufacturer decides about the number of retailers $D_{U 1}, \ldots, D_{U m}$ it supplies directly and, thus, also determines the number of retailers $D_{M m+1}, \ldots, D_{M n}$ to be supplied by the intermediary. In any subsequent period $t$, the deliveries to the downstream retailers and the retailers' sales to the final consumers take place.

All interactions along the value chain are based on non-linear contracts. ${ }^{11}$ Any supplier dealing with the downstream firms - the manufacturer and/or the intermediary - makes simultaneous and secret take-it-or-leave-it offers to its respective retailers. The take-it-or-leave-it offers take the form of quantity-forcing contracts $T_{i j}\left(q_{i j}, F_{i j}\right)$, specifying the quantity $q_{i j}$ the retailer $D_{i j}$ can purchase at the lump-sum price $F_{i j}$. When making use of the intermediary, the manufacturer negotiates first with the intermediary about a complex contract $T_{M}\left(Z, X, Q_{M}\right)$ consisting of an upfront payment $Z$ to be made by the intermediary upon successful negotiations

\footnotetext{
${ }^{9}$ In addition to the costs associated with the distribution to the retailers, $K$ could also comprise expenses for some final processing and customization.

${ }^{10}$ Note that the number of retailers $m$ the upstream firm supplies directly will be endogenously determined.

${ }^{11}$ Note that non-linear tariffs are a standard remedy for the double-marginalization problem (see Tirole 1988). Furthermore, they account for the fact that vertical relations are often based on more complex contracts than simple linear pricing rules (Rey and Vergé 2008). Moreover, non-linear tariffs are commonly used in intermediategoods markets. Empirical evidence is provided by Bonnet and Dubois (2010) and Berto Villas-Boas (2007).
} 
and a conditional payment $X$ to be made by the intermediary if it actually purchases the fixed quantity $Q_{M}:^{12}$

$$
T_{M}\left(Z, X, Q_{M}\right)=\left\{\begin{array}{ll}
Z+X & \text { if } M \text { purchases } Q_{M} \\
Z & \text { if } M \text { makes no purchase }
\end{array} .\right.
$$

That is, in exchange for the upfront payment $Z$, the intermediary obtains the option to purchase the quantity $Q_{M}$ at the price $X$. The intermediary orders the predetermined quantity $Q_{M}$ and executes the payment $X$ only after its initially assigned retailers have accepted the intermediary's offer.

Note that under a simple quantity-forcing contract, the upstream firm would always have an incentive to cheat the intermediary by directly delivering to all retailers and, thus, outpacing the intermediary after having received the fixed payment from the intermediary. Anticipating this upstream firm's opportunistic behavior, the intermediary would never participate in the gameunless $U$ could commit to the initially determined market structure. ${ }^{13}$ To ensure the intermediary's participation, the firms agree on the more complex delivery contract $T_{M}\left(Z, X, Q_{M}\right)$. The optional purchase of $Q_{M}$ and, thus, the conditionality of the payment $X$ ensure that the manufacturer never has an incentive to circumvent the intermediary after having received the upfront payment $Z$. In the case of a negative $Z$, indicating an upfront payment by the upstream firm, we show that the intermediary's profit is higher when actually buying $Q_{M}$ for further distribution to the downstream retailers than when simply pocketing the upfront payment $Z$ as long as $\alpha$ is sufficiently low. Note further that the intermediary can never deviate from the initially determined industry structure by making competing offers to the retailers originally assigned to the manufacturer since it is constrained by its purchase of the predetermined quantity $Q_{M} \cdot{ }^{14}$

In each period, the retailers $D_{i j}$ face an inverse demand function $P_{i j}\left(q_{i j}, Q_{-j}\right)$, where $q_{i j}$ denotes the quantity of retailer $D_{i j}$ and $Q_{-j}=\sum_{k \neq j} q_{i k}$ refers to the quantity sold by all other retailers. The retailers' inverse demand functions are twice continuously differentiable and decreasing in $q_{i j}$ and $q_{i k}, k \neq j$. For simplicity, we assume that the inverse demand functions are symmetric, i.e. $P_{i j}\left(q_{i j}, Q_{-j}\right)=P\left(q_{i j}, Q_{-j}\right)$, with $\partial P_{i j}(\cdot) / \partial q_{i j}<\partial P_{i j}(\cdot) / \partial q_{i k}<0 .{ }^{15}$ To ensure concavity of the revenue functions, we further assume $\left(\partial^{2} P_{i j}(\cdot) / \partial q_{i j}^{2}\right) q_{i j}+2 \partial P_{i j}(\cdot) / \partial q_{i j}<0$.

\footnotetext{
${ }^{12}$ The assumption of complex contracts is increasingly applied in the literature. Marx and Shaffer (2007) and Miklós-Thal et al. (2011), for example, make use of three-part-tariff contracts.

${ }^{13}$ For example, the upstream firm would not have an incentive to cheat the intermediary if the re-organization of the delivery structure would be sufficiently costly or if the exclusive retail-supply relation initially granted to the intermediary could be made legally binding. In such cases, a simple quantity-forcing or two-part-tariff contract could be implemented between $U$ and $M$.

${ }^{14}$ Note that the intermediary's potential incentive to supply the retailers initially assigned to the manufacturer could also be destroyed by a three-part-tariff contract combined with a predetermined maximum quantity the intermediary is allowed to purchase from the manufacturer.

${ }^{15}$ To simplify the notation, we omit the arguments of the functions where this does not lead to any confusion.
} 
To summarize, in each period $t$, we consider the following game (see Figure 1): First, the players of the game agree on their respective delivery contracts, depending on the ex-ante chosen distribution system. In the case of integrated distribution, the first stage of the game is considered as follows:

- Stage 1: Take-it-or-leave-it offers from $U$ to $D_{U j}$. The upstream manufacturer $U$ makes simultaneous and secret take-it-or-leave-it offers $T_{U j}\left(q_{U j}, F_{U j}\right)$ to the downstream firms $D_{U j}$. Each retailer observes only its own offer and decides whether to accept or reject it.

In the cases of mixed and disintegrated distribution, the deliveries rely both on upstream negotiations between the manufacturer and the intermediary and on take-it-or-leave-it offers to the downstream retailers - made by the intermediary and potentially by the manufacturer. ${ }^{16}$

- Stage 1a: Upstream negotiations. The upstream firm $U$ negotiates with the intermediate firm $M$ about the delivery contract $T_{M}\left(Z, X, Q_{M}\right)$. In the case of successful negotiations, the upfront payment $Z$ is made by the intermediary. The terms of delivery do not become public. For simplicity, however, we assume that a negotiation breakdown between $U$ and $M$ is publicly observable.

- Stage 1b: Downstream take-it-or-leave-it offers. The intermediate firm $M$ and potentially the upstream firm $U$ make simultaneous and secret take-it-or-leave-it offers $T_{M j}\left(q_{M j}, F_{M j}\right)$ and $T_{U j}\left(q_{U j}, F_{U j}\right)$, respectively, to their corresponding downstream firms $D_{M j}$ and $D_{U j}$. Each retailer observes only its own offer and decides whether to accept or reject it.

- Stage 1c: Payment of $X$. If the intermediary actually buys the predetermined quantity $Q_{M}$, it pays $X$ to the upstream manufacturer.

For any distribution system, the stage game continues as follows:

- Stage 2: Downstream competition. Without knowing the terms of delivery offered to their rivals, the retailers $D_{i j}$ having accepted the contract in the previous stage compete in quantities. Finally, all players observe the prices that realize in the final-consumer market.

Our equilibrium concept is perfect Bayesian equilibrium. We assume that the take-it-orleave-it offers made to the downstream firms are secret and do not become public knowledge before the retailers enter into downstream competition (interim unobservability). In fact, the terms of delivery never become public. That is, the retailer $D_{i j}$ observes only its own offer but not the offers made to the retailers $D_{i k}, k \neq j$. Furthermore, the retailers do not observe the

\footnotetext{
${ }^{16}$ Note that all retailers are supplied by the intermediary for $m=0$, implying that no offers are made by the manufacturer to the retailers.
} 


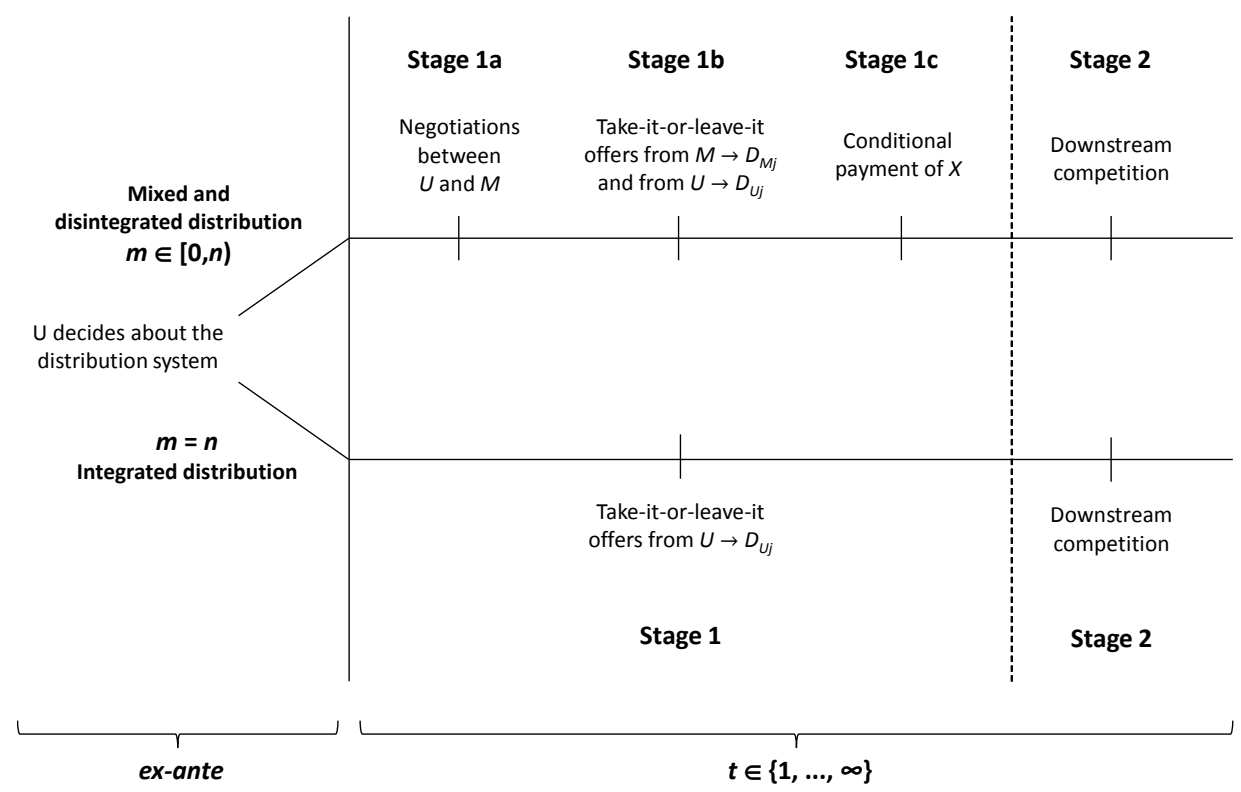

Figure 1: Sequence of Moves

negotiation outcome between the intermediary and the manufacturer. The equilibrium analysis requires an assumption on how the downstream firms revise their beliefs about the offers made to the rivals when receiving an out-of-equilibrium offer. We assume that the retailers hold passive beliefs (see, e.g., Hart and Tirole 1990; McAfee and Schwartz 1994). ${ }^{17}$ That is, even if it is offered an out-of-equilibrium contract, each retailer believes that the rival retailers still receive the equilibrium contract. Likewise, the manufacturer and the intermediary do not observe each other's offers to the retailers. Consistently with the retailers' beliefs, we assume that the intermediary holds passive beliefs in the negotiations with the manufacturer. The manufacturer, however, knows that the intermediary cannot sell more to its assigned retailers than the quantity it gets. Note that the belief system does not depend on the chosen distribution structure since the use of the intermediary does not alter the marginal costs of production and since the retailers are, thus, indifferent between buying from the upstream firm or the intermediary.

All firms aim at maximizing the discounted sum of their future profits over an infinite time horizon, using the common discount factor $\delta \in[0,1)$. For all three possible distribution systems, we analyze the conditions for the existence of perfectly or imperfectly collusive equilibria which allow the manufacturer and, if active, the intermediary to obtain higher profits than under the Cournot-Nash equilibrium, i.e. the unique equilibrium in any stage game. Note that imperfect collusion refers to any equilibrium in which the upstream firm and the intermediary can commit

\footnotetext{
${ }^{17}$ Passive beliefs constitute a natural belief structure reflecting Nash-equilibrium reasoning, whereby a deviation by the supplier is interpreted as a tremble of the hand (cf. McAfee and Schwartz 1995).
} 
to sell lower quantities than in the Cournot-Nash equilibrium, while perfect collusion is obtained when the overall industry profit is maximized. We assume that the collusive equilibria are sustained through infinite Nash reversion by the retailers. ${ }^{18}$ That is, after all profits have realized at the end of each period, the retailers react to any deviation from the collusive equilibrium strategy by only accepting the non-collusive, Cournot-Nash equilibrium offers from the next period onwards.

The downstream firms' profits in each period $t$ are given by: ${ }^{19}$

$$
\pi_{D_{i j}}=P\left(q_{i j}, Q_{-j}\right) q_{i j}-F_{i j}
$$

The per-period profit of the upstream firm refers to:

$$
\pi_{U}=\left\{\begin{array}{ll}
\sum_{j=1}^{n}\left(F_{U j}-c q_{U j}\right)-n K & \text { if } m=n \\
\sum_{j=1}^{m} F_{U j}+Z+X-c\left(\sum_{j=1}^{m} q_{U j}+\sum_{j=m+1}^{n} q_{M j}\right)-m K & \text { if } m \in[0, n)
\end{array},\right.
$$

while the profit of the intermediate firm $M$ in period $t$ is given by:

$$
\pi_{M}=\left\{\begin{array}{ll}
0 & \text { if } m=n \\
\sum_{j=m+1}^{n} F_{M j}-Z-X-(n-m) \alpha K & \text { if } m \in[0, n)
\end{array} .\right.
$$

\section{Equilibrium Analysis}

In this section, we study the impact of the distribution systems on the sustainability of collusion in the considered vertical industry structure when the retailers play an infinite Nash reversion strategy. We start with the case of integrated distribution (I), i.e. $m=n$, and then turn to the combined analysis of mixed and disintegrated distribution (MD), i.e. $m \in[0, n)$. For each distribution system, we first analyze the non-collusive equilibrium, which serves as a punishment by the downstream firms for any deviation from the collusive equilibrium path. We then turn to the analysis of the collusive equilibria and the possible deviation strategies of the manufacturer and, if active, the intermediate firm.

As a benchmark for our further analyses, we derive the quantities that maximize the industry profit under vertical integration:

$$
q_{i j}^{\max }:=\arg \max _{q_{i j}} \Pi-n K
$$

\footnotetext{
${ }^{18}$ Infinite Nash reversion strategies - pioneered by Friedman (1971) - are commonly applied in the literature, see, e.g., Nocke and White $(2007 ; 2010)$ as well as Piccolo and Reisinger (2011).

${ }^{19}$ For simplicity, we omit the subscript $t$ in the profit functions.
} 
where $\Pi:=\sum_{j}\left(P\left(q_{i j}, Q_{-j}\right)-c\right) q_{i j}$ indicates the industry profit net of fixed costs. The respective first-order conditions refer to:

$$
\left.\left(P\left(q_{i j}, Q_{-j}\right)-c+\frac{\partial P\left(q_{i j}, Q_{-j}\right)}{\partial q_{i j}} q_{i j}+\sum_{k \neq j} \frac{\partial P\left(q_{i k}, Q_{-k}\right)}{\partial q_{i j}} q_{i k}\right)\right|_{q_{i j}=q_{i j}^{\max }}=0 .
$$

Using symmetry, we get $q_{i j}^{\max }=q_{i k}^{\max }=q^{\max }$ and denote $\bar{\Pi}^{\max }:=\Pi\left(q^{\max }\right)$.

\subsection{Integrated Distribution}

For $m=n$, the manufacturer supplies its input directly to all downstream retailers. The delivery to each retailer is based on the standard quantity-forcing contract $T_{U j}\left(q_{U j}, F_{U j}\right)$. Note that the manufacturer has an incentive to behave opportunistically when delivering directly to the retailers, which cannot be overcome by implementing a complex contract scheme.

\subsubsection{Non-Collusive Equilibrium}

Each retailer accepts the take-it-or-leave-it offer made by $U$ as long as its profit is not negative. Thus, the upstream firm uses the fixed fees to extract the entire profit from each downstream firm. Holding passive beliefs, the retailers expect the rival retailers to receive the equilibrium offer from the manufacturer and, thus, to sell the equilibrium quantity in the downstream market. Denoting by $\underline{Q}_{-j}^{e}$ the sum of the equilibrium quantities set by all rival retailers, the respective fixed fee for retailer $D_{U j}$ is given by:

$$
\underline{F}_{U j}=P\left(q_{U j}, \underline{Q}_{-j}^{e}\right) q_{U j}
$$

The manufacturer offers a quantity $\underline{q}_{U j}$ to each retailer so as to maximize its profit. Due to our assumptions of passive beliefs and interim unobservability, the equilibrium quantity choice $\underline{q}_{U j}$ affects the upstream firm's profit only through $\left(P\left(q_{U j}, \underline{Q}_{-j}^{e}\right)-c\right) q_{U j}$. We, thus, have:

$$
\underline{q}_{U j}:=\arg \max _{q_{U j}}\left(P\left(q_{U j}, \underline{Q}_{-j}^{e}\right)-c\right) q_{U j}
$$

The corresponding first-order conditions refer to:

$$
\left.\left(P\left(q_{U j}, \underline{Q}_{-j}^{e}\right)-c+\frac{\partial P\left(q_{U j}, \underline{Q}_{-j}^{e}\right)}{\partial q_{U j}} q_{U j}\right)\right|_{q_{U j}=\underline{q}_{U j}}=0
$$

This implies that the manufacturer offers its retailers to purchase the standard Cournot quantity $\underline{q}_{U j}=\underline{q}_{U k}=\underline{q}$ at the lump-sum payment $\underline{F}_{U j}=\underline{F}_{U k}=\underline{F}$, which fully extracts the 
corresponding downstream rents. ${ }^{20}$

The manufacturer cannot exploit its monopoly position vis-à-vis the retailers by reducing or even eliminating downstream competition. This result traces back to the well-known opportunism problem in vertical contracting, first identified by Hart and Tirole (1990). Suppose that retailer $D_{U j}$ has accepted a contract ensuring the monopoly quantity in the downstream market and a corresponding fixed fee extracting the downstream rent. Then, the upstream firm has an incentive to increase the quantities offered to all other retailers $D_{U k}, k \neq j$, in order to free-ride on the contract with $D_{U j}$. This opportunistic behavior of $U$ is anticipated by the retailers such that they never accept a contract offer different from $(\underline{q}, \underline{F}){ }^{21}$

Using our results and denoting $\underline{Q}:=n \underline{q}$, the associated profit of the upstream firm refers to: $:^{22}$

$$
\begin{aligned}
& \underline{\pi}_{U}^{I}(\underline{q})=n(P(\underline{Q})-c) \underline{q}-n K=\underline{\Pi}-n K, \\
& \quad \text { with: } \underline{\Pi}:=n(P(\underline{Q})-c) \underline{q},
\end{aligned}
$$

while all downstream firms make zero profits.

\subsubsection{Collusive Equilibria}

Let us now turn to the collusive equilibria that can be sustained in the infinitely repeated game. In each period $t$, the manufacturer can soften downstream competition by reducing the quantity offered to each retailer, whereby the industry profit is maximized if all retailers sell $q^{\max }$ in the downstream market (see 5). This implies that there exists a continuum of symmetric equilibrium quantities $\bar{q}_{U j}=\bar{q}_{U k}=\bar{q} \in\left[q^{\max }, \underline{q}\right)$, resulting in higher profits than in the Cournot-Nash equilibrium. ${ }^{23}$ Holding passive beliefs, each retailer expects its rivals to receive the equilibrium offer from the upstream firm $U$. Correspondingly, each retailer anticipates the sum of the rivals' equilibrium quantities to be $\bar{Q}_{-j}^{e}<\underline{Q}_{-j}^{e}$. As in the non-collusive Cournot-Nash equilibrium, the

\footnotetext{
${ }^{20}$ Note that the quantity constraint imposed on each retailer by the upstream firm's take-it-or-leave-it offer is always binding when the retailers compete in the downstream market. Maximizing their profits given in (2), the retailers would prefer to sell more to the consumers than what they get from the upstream firm as they do not account for the manufacturer's marginal cost of production.

${ }^{21}$ The opportunism problem disappears if the buyers hold symmetric beliefs (McAfee and Schwartz 1994), while the commitment problem still arises under wary beliefs as introduced by McAfee and Schwartz (1994). Note further that in our framework, i.e. under downstream quantity competition and interim unobservability of the delivery contracts, the non-collusive equilibrium under wary beliefs is the same as under passive beliefs (see Rey and Vergé 2004).

${ }^{22}$ Note that we assume $K<\underline{\Pi} / n$ to fulfill the upstream firm's participation constraint in the case of integrated distribution.

${ }^{23}$ Note that our restriction to $\bar{q} \in\left[q^{\max }, q\right)$ is without loss of generality since, for any $q_{U j}<q^{\max }$, there exists a corresponding $q_{U j}>q^{\max }$ which leads to the same industry profit. Thereby, $q_{U j}>q^{\max }$ weakly dominates $q_{U j}<q^{\max }$ since the scope for profitable deviations from $q_{U j}>q^{\max }$ is lower than from $q_{U j}<q^{\max }$ (see Piccolo and Miklós-Thal 2012).
} 
upstream manufacturer uses the fixed fees to extract the rents from the downstream retailers, i.e. $\bar{F}=P\left(\bar{q}, \bar{Q}_{-j}^{e}\right) \bar{q}$ (cf. equation 7). Denoting $\bar{Q}:=n \bar{q}$, the profit of the upstream manufacturer along the collusive equilibrium path is given by:

$$
\bar{\pi}_{U}^{I}(\bar{q})=n(P(\bar{Q})-c) \bar{q}-n K=\bar{\Pi}(\bar{q})-n K,
$$

where

$$
\bar{\Pi}(\bar{q}):=n(P(\bar{Q})-c) \bar{q} \leq \bar{\Pi}^{\max }
$$

indicates the industry profit net of fixed costs on the collusive equilibrium path. The downstream firms, in turn, earn zero profits.

Consider now that the upstream firm deviates from the collusive equilibrium path by offering each downstream firm $D_{U j}$ a quantity $q_{U j}$ exceeding $\bar{q}$. Due to their passive beliefs, the retailers expect that their rivals still obtain the equilibrium quantity when receiving such an out-ofequilibrium offer. Again, the upstream firm uses the fixed fees to capture the corresponding profits of the downstream firms (cf. equation 7):

$$
\widetilde{F}_{U j}=P\left(q_{U j}, \bar{Q}_{-j}^{e}\right) q_{U j}
$$

and sets the quantities so as to maximize its profit:

$$
\widetilde{q}_{U j}:=\arg \max _{q_{U j}}\left(P\left(q_{U j}, \bar{Q}_{-j}^{e}\right)-c\right) q_{U j}
$$

The corresponding first-order conditions refer to:

$$
\left.\left(P\left(q_{U j}, \bar{Q}_{-j}^{e}\right)-c+\frac{\partial P\left(q_{U j}, \bar{Q}_{-j}^{e}\right)}{\partial q_{U j}} q_{U j}\right)\right|_{q_{U j}=\widetilde{q}_{U j}}=0
$$

Note that, under deviation, each retailer sells more in the downstream market than in the non-collusive equilibrium, i.e. $\widetilde{q}_{U j}=\widetilde{q}_{U k}=\widetilde{q}>\underline{q}$ since $\bar{Q}_{-j}^{e}<\underline{Q}_{-j}^{e}{ }^{24}$ Correspondingly, we get $\widetilde{F}_{U j}=\widetilde{F}_{U k}=\widetilde{F}>\bar{F}>\underline{F}$. Note further that the manufacturer always deviates with all retailers. This is due to the fact that the retailers respond to any deviation from the collusive equilibrium path by turning to infinite Nash reversion in all subsequent periods. The upstream firm's deviation profit, therefore, refers to:

$$
\tilde{\pi}_{U}^{I}(\widetilde{q}, \bar{q})=n\left(P\left(\widetilde{q}, \bar{Q}_{-j}\right)-c\right) \widetilde{q}-n K
$$

\footnotetext{
${ }^{24}$ Evaluating (16) for $q_{U j}=\underline{q}$, we get $\left.\left(P\left(q_{U j}, \bar{Q}_{-j}^{e}\right)-c+\left(\partial P\left(q_{U j}, \bar{Q}_{-j}^{e}\right) / \partial q_{U j}\right) q_{U j}\right)\right|_{q_{U j}=q}>0$ since $\bar{Q}_{-j}^{e}<$ $\underline{Q}_{-j}^{e}$. Thus, we must have $\widetilde{q}>\underline{q}$.
} 
where we have $\bar{Q}_{-j}=(n-1) \bar{q}=\bar{Q}_{-j}^{e}$. For later reference, we rewrite the profit of the upstream deviant as:

$$
\tilde{\pi}_{U}^{I}(\widetilde{q}, \bar{q})=\bar{\pi}_{U}^{I}(\bar{q})+n \Delta(\widetilde{q}, \bar{q})
$$

where $\Delta(\widetilde{q}, \bar{q}):=\left(P\left(\widetilde{q}, \bar{Q}_{-j}\right)-c\right) \widetilde{q}-(P(\bar{Q})-c) \bar{q}$ indicates the additional profit of the manufacturer from deviating with any given retailer. In other words, $\Delta(\widetilde{q}, \bar{q})$ corresponds to the loss imposed on each retailer by the upstream firm's opportunistic behavior. It follows from (15) that $\Delta(\widetilde{q}, \bar{q})$ is strictly positive.

Collusion is only sustainable if the upstream firm has no incentive to deviate. There exists a continuum of symmetric equilibrium quantities $\bar{q}$ which ensure that the upstream manufacturer's corresponding incentive constraint holds:

$$
\frac{1}{1-\delta} \bar{\pi}_{U}^{I}(\bar{q}) \geq \tilde{\pi}_{U}^{I}(\widetilde{q}, \bar{q})+\frac{\delta}{1-\delta} \underline{\pi}_{U}^{I}(\underline{q})
$$

We select the Pareto-dominant equilibria, i.e. those corresponding to the lowest possible symmetric quantities fulfilling the incentive constraint given in (19). Thereby, perfect collusion, i.e. $q^{\max }$, can be sustained if:

$$
\delta \geq \delta^{I}:=\frac{n \Delta\left(\widetilde{q}, q^{\max }\right)}{\bar{\Pi}^{\max }-\underline{\Pi}+n \Delta\left(\widetilde{q}, q^{\max }\right)} .
$$

For $\delta<\delta^{I}$, however, only imperfect collusion is sustainable. The respective symmetric equilibrium quantities $\overline{\bar{q}}^{I}>q^{\max }$ are implicitly given by:

$$
\frac{1}{1-\delta} \bar{\pi}_{U}^{I}\left(\overline{\bar{q}}^{I}\right) \equiv \widetilde{\pi}_{U}^{I}\left(\widetilde{q}, \overline{\bar{q}}^{I}\right)+\frac{\delta}{1-\delta} \underline{\pi}_{U}^{I}(\underline{q})
$$

Note that $\overline{\bar{q}}^{I}$ is decreasing in $\delta$ as the upstream firm's incentive to deviate is decreasing in $\delta .{ }^{25}$ That is, for $\delta \rightarrow 0$, we obtain $\overline{\bar{q}}^{I} \rightarrow \underline{q}$, while we have $\overline{\bar{q}}^{I} \rightarrow q^{\max }$ for $\delta \rightarrow \delta^{I}$. The equilibrium quantities under integrated distribution are, thus, given by:

$$
\bar{q}^{I}=\left\{\begin{array}{ll}
q^{\max } & \text { if } \delta \geq \delta^{I} \\
\bar{q}^{I} & \text { if } \delta<\delta^{I}
\end{array} .\right.
$$

Summarizing our results, we get:

Lemma 1 For any $\delta \geq \delta^{I}$, perfect collusion can be sustained under integrated distribution, implying $\bar{\pi}_{U}^{I}\left(q^{\max }\right)$. For any $\delta<\delta^{I}$, however, only imperfect collusion is sustainable, resulting in $\bar{\pi}_{U}^{I}\left(\overline{\bar{q}}^{I}\right)$. Note that $\overline{\bar{q}}^{I}$ is decreasing in $\delta$, leading to a higher collusive profit of the upstream firm for higher $\delta$.

Proof. See the Appendix.

\footnotetext{
${ }^{25}$ For the proof, see the Appendix (proof of Lemma 1).
} 


\subsection{Mixed and Disintegrated Distribution}

We now proceed with the analysis of the mixed and disintegrated distribution systems (MD), where the upstream firm delivers directly to $m \in[0, n)$ retailers $D_{U 1}, \ldots, D_{U m}$ and uses the intermediary $M$ to distribute its product exclusively to the remaining $n-m$ retailers $D_{M m+1}, \ldots, D_{M n}$. That is, each supplier - the upstream firm and the intermediary - has a monopoly position visà-vis its respective retailers. ${ }^{26}$

Before the delivery to the retailers takes place, the upstream manufacturer negotiates with the intermediary about a contract $T_{M}\left(Z, X, Q_{M}\right)$, where $Z$ specifies an upfront payment to be made by the intermediary upon successful negotiations. In exchange for $Z$, the intermediary obtains the option to purchase the quantity $Q_{M}$ at the price $X$. The intermediary orders $Q_{M}$ and pays $X$ only if the intermediary is able to supply $Q_{M}$ to the downstream firms $D_{M m+1}, \ldots, D_{M n}$. This is the case when the upstream firm has not placed competing offers to the $n-m$ retailers initially assigned to the intermediary.

Note that the intermediary never deviates from the initially determined industry structure. First, it has no incentive to make competing offers to the retailers ex-ante assigned to be directly supplied by the manufacturer as it can only purchase the predetermined quantity $Q_{M}$. Second, if $Z$ is negative, the intermediary has no incentive to simply pocket the upfront payment it receives from the upstream firm. It prefers to sell $Q_{M}$ to the retailers and, thus, to pay the conditional fee if its cost advantage in distribution is sufficiently large.

\subsubsection{Non-Collusive Equilibrium}

In the non-collusive equilibrium, both the manufacturer and the intermediary make simultaneous and secret take-it-or-leave-it offers to their respective retailers. Both firms use the fixed fees $\underline{F}_{i j}^{M D}=P\left(q_{i j}, \underline{Q}_{-j}^{e}\right) q_{i j}$ to fully extract the rents from the downstream retailers. Correspondingly, the quantity the manufacturer offers to each of its retailers refers to: ${ }^{27}$

$$
\underline{q}_{U j}^{M D}:=\arg \max _{q_{U j}}\left(P\left(q_{U j}, \underline{Q}_{-j}^{e}\right)-c\right) q_{U j}
$$

inducing the corresponding first-order conditions:

$$
\left.\left(P\left(q_{U j}, \underline{Q}_{-j}^{e}\right)-c+\frac{\partial P\left(q_{U j}, \underline{Q}_{-j}^{e}\right)}{\partial q_{U j}} q_{U j}\right)\right|_{q_{U j}=\underline{q}_{U j}^{M D}}=0 .
$$

\footnotetext{
${ }^{26}$ For $m=0$, the retailers are only supplied by the intermediary.

${ }^{27}$ As already indicated above, the quantity-maximization problems are separable due to our assumptions of passive beliefs and interim unobservability. That is, the choice of $q_{U j}$ does not affect the choice of $q_{U k}, k \neq j$, and $q_{M j}$.
} 
As a consequence, the unique equilibrium quantities $\underline{q}_{U j}^{M D}=\underline{q}_{U k}^{M D}=\underline{q}$ offered by $U$ correspond to the standard Cournot outcome (cf. equation 9). The intermediary's offers to the downstream retailers, in turn, are determined by the negotiation outcome with the manufacturer. In their negotiations, the manufacturer and the intermediary agree on a quantity $\underline{Q}_{M}=\sum_{j=m+1}^{n} \underline{q}_{M j}^{M D}$ so as to maximize their joint profit. Due to the above-described separability of the quantity choice, this simplifies to the maximization of:

$$
\underline{q}_{M j}^{M D}:=\arg \max _{q_{M j}}\left(P\left(q_{M j}, \underline{Q}_{-j}^{e}\right)-c\right) q_{M j}
$$

The respective first-order conditions are, thus, given by:

$$
\left.\left(P\left(q_{M j}, \underline{Q}_{-j}^{e}\right)-c+\frac{\partial P\left(q_{M j}, \underline{Q}_{-j}^{e}\right)}{\partial q_{M j}} q_{M j}\right)\right|_{q_{M j}=\underline{q}_{M j}^{M D}}=0
$$

which directly implies that the intermediary offers each of its retailers the Cournot quantity $\underline{q}_{M j}^{M D}=\underline{q}_{M k}^{M D}=\underline{q}$. As a consequence, we further obtain $\underline{F}_{U j}^{M D}=\underline{F}_{M j}^{M D}=\underline{F}$. Using our results, the manufacturer's and the intermediary's reduced profit functions are given by:

$$
\underline{\pi}_{U}^{M D}=m(P(\underline{Q})-c) \underline{q}+Z+X-(n-m) \underline{q}-m K
$$

and

$$
\underline{\pi}_{M}^{M D}=(n-m) P(\underline{Q}) \underline{q}-Z-X-(n-m) \alpha K,
$$

while the downstream firms earn zero profits.

The negotiating parties share the maximized joint profit by the upfront payment $Z$, taking the conditional payment $X$ is as given. ${ }^{28}$ Thereby, we assume that the manufacturer makes a take-itor-leave-it offer to the intermediate firm with probability $\beta \in[0,1]$, while the intermediary makes a take-it-or-leave-it offer to the upstream firm with probability $1-\beta .{ }^{29}$ Since the intermediate firm has no alternative supplier for the input provided by $U$, it accepts any offer as long as its profit does not become negative. In the case of $\beta=1$, the upstream manufacturer, thus, fully extracts the intermediary's profit, resulting in:

$$
\underline{Z}_{U}=(n-m)(P(\underline{Q}) \underline{q}-\alpha K)-X .
$$

\footnotetext{
${ }^{28}$ To obtain a parsimonious model of negotiations, we combine both non-cooperative and cooperative solution concepts in our model as commonly done in the literature (see Inderst and Shaffer 2007). For a non-cooperative foundation of the asymmetric Nash-bargaining solution, see Binmore et al. (1986).

${ }^{29}$ The probabilities could also reflect exogenously given bargaining power of the players in bilateral negotiations, capturing asymmetries between the negotiating parties such as non-identical beliefs about the probability of a negotiation breakdown (Binmore et al. 1986).
} 
If, instead, the intermediary has the full take-it-or-leave-it power, it has to provide the manufacturer at least with its outside option when supplying all retailers directly, i.e. $\underline{\Pi}-n K$ (see 10). For $\beta=0$, the fixed fee, thus, refers to:

$$
\underline{Z}_{M}=-[m(P(\underline{Q}) \underline{q}-K)-n c \underline{q}+X]+\underline{\Pi}-n K \text {. }
$$

The equilibrium upfront payment constitutes a linear combination of (29) and (30), resulting in $\underline{Z}=\beta \underline{Z}_{U}+(1-\beta) \underline{Z}_{M}$.

After having received the upfront payment $Z$, the manufacturer would benefit from circumventing the intermediary and directly delivering to all retailers itself. To attract the retailers initially assigned to the intermediary, the manufacturer simply needs to offer each of them a fixed fee $\underline{F}-\varepsilon$, while keeping the offered quantity constant at $\underline{q}$. Correspondingly, the deviation profit of the manufacturer refers to:

$$
\underline{\tilde{\pi}}_{U}^{M D}(\underline{q})=n(P(\underline{Q})-c) \underline{q}+\underline{Z}-n K \text {. }
$$

To deter the manufacturer from behaving opportunistically, the payment $\underline{X}$-which the intermediary only pays if it actually buys $\underline{Q}_{M}$-is set so as to make the upstream firm indifferent between cheating the intermediary and sticking to the ex-ante determined distribution structure. The conditional fee, therefore, corresponds to the manufacturer's additional profit when circumventing the intermediary:

$$
\underline{X}=(n-m)[P(\underline{Q}) \underline{q}-K] .
$$

It follows immediately that $\underline{X}$ is decreasing in the number of retailers the manufacturer supplies directly, i.e. $m$. The extent of $\underline{X}$, however, never affects the distribution of the rents between $U$ and $M$. The upfront payment simplifies to $\underline{Z}=\beta(1-\alpha)(n-m) K \geq 0$ when using $\underline{X}$ as given in (32). $\underline{Z}$ is weakly positive, indicating a license fee or a franchise fee to be paid by the intermediary.

Using our results, the non-collusive equilibrium profit of the upstream firm is given by:

$$
\underline{\pi}_{U}^{M D}(\underline{q})=\beta(1-\alpha)(n-m) K+\underline{\Pi}-n K .
$$

That is, the manufacturer gets its outside option plus a share of the economies in $K$, which trace back to the intermediary's potential competitive advantage in the delivery to the retailers. Having no outside option, the intermediary simply gets its share of the economies in $K$ :

$$
\underline{\pi}_{M}^{M D}(\underline{q})=(1-\beta)(1-\alpha)(n-m) K .
$$


Lemma 2 For $\beta>0$ and $\alpha<1$, the manufacturer's non-collusive equilibrium profit under mixed or disintegrated distribution strictly exceeds the manufacturer's non-collusive equilibrium profit under integrated distribution, i.e. $\underline{\pi}_{U}^{M D}(\underline{q})>\underline{\pi}_{U}^{I}(\underline{q})$. For $\beta=0$ or $\alpha=1$, both profits coincide.

Lemma 2 underlines the manufacturer's incentive to agree on a complex supply contract $T_{M}\left(Z, X, Q_{M}\right)$ in order to commit itself to the initially selected industry structure as long as the intermediary is more efficient than the manufacturer in delivering to the retailers, i.e. $\alpha<1$, and as long as the manufacturer has some bargaining power in the negotiations with the intermediary, i.e. $\beta>0$. For $\alpha=1$ or $\beta=0$, the manufacturer earns exactly the same profit as under integrated distribution and is, thus, indifferent which distribution system to choose.

\subsubsection{Collusive Equilibria}

In the infinitely repeated game, we focus on the continuum of symmetric collusive equilibria where both the manufacturer and the intermediary offer each of their respective retailers a quantity which undercuts $\underline{q}$, i.e. $\bar{q} \in\left[q^{\max }, \underline{q}\right)$, inducing softer downstream competition. The corresponding fixed fees are used to fully extract the downstream rents and, thus, refer to $\bar{F}=P(\bar{Q}) \bar{q}$. In their negotiations, the upstream manufacturer and the intermediary agree on a quantity $\bar{Q}_{M}=(n-m) \bar{q}$. They share their joint profit according to their exogenously given bargaining power via the upfront payment $\bar{Z}$, taking into account the conditional payment $X$. Analogously to above, the upfront payment refers to $\bar{Z}=\beta \bar{Z}_{U}+(1-\beta) \bar{Z}_{M}$, with:

$$
\bar{Z}_{U}=(n-m)(P(\bar{Q}) \bar{q}-\alpha K)-X
$$

and

$$
\bar{Z}_{M}=-[m(P(\bar{Q}) \bar{q}-K)-n c \bar{q}+X]+\underline{\Pi}-n K .
$$

Even on the collusive equilibrium path, the manufacturer's outside option is given by $\underline{\Pi}-n K$. If the manufacturer and the intermediary fail to achieve an agreement, the manufacturer decides to deliver to all retailers directly. However, the manufacturer cannot commit not to re-enter into negotiations with the intermediary in the subsequent period. Correspondingly, the $n-m$ retailers initially supplied by the intermediary do not expect to be in an infinitely repeated interaction with the manufacturer and, thus, only accept the non-collusive equilibrium contract $(q, \underline{F})$. Assuming that the $m$ retailers supplied by $U$ observe the negotiation breakdown between the manufacturer and the intermediary, they expect the manufacturer to offer the other $n-m$ retailers the equilibrium contract $(\underline{q}, \underline{F})$. The $m$ retailers, therefore, only accept a contract $(\underline{q}, \underline{F})$ although they are in an infinitely repeated interaction with $U$.

Given the upfront payment $\bar{Z}$, the manufacturer has an incentive to outbid the interme- 
diary by directly delivering to all retailers itself. Thereby, the manufacturer offers the $n-m$ retailers initially assigned to the intermediary a deviant contract $(\widetilde{q}, \widetilde{F})$ as defined in (14) and (15). To prevent the manufacturer from deviating from the given distribution structure, the negotiating parties set the conditional payment $\bar{X}$ so as to make the upstream firm indifferent between circumventing the intermediary and not behaving opportunistically. Having also an incentive to offer $(\widetilde{q}, \widetilde{F})$ to its own $m$ retailers, the upstream firm's reduced profit function when circumventing the intermediary is given by:

$$
\widetilde{\pi}_{U}^{M D}(\widetilde{q}, \bar{q})=m\left[\left(P\left(\widetilde{q}, \bar{Q}_{-j}\right)-c\right) \widetilde{q}-K\right]+\bar{Z}+(n-m)\left[\left(P\left(\widetilde{q}, \bar{Q}_{-j}\right)-c\right) \widetilde{q}-K\right]
$$

The fixed payment $\bar{X}$ needs to make the manufacturer indifferent to:

$$
\widetilde{\widetilde{\pi}}_{U}^{M D}(\widetilde{q}, \bar{q})=m\left[\left(P\left(\widetilde{q}, \bar{Q}_{-j}\right)-c\right) \widetilde{q}-K\right]+\bar{Z}+\bar{X}-(n-m) c \bar{q} .
$$

Consequently, we have:

$$
\bar{X}=(n-m)\left[P\left(\widetilde{q}, \bar{Q}_{-j}\right) \widetilde{q}-c(\widetilde{q}-\bar{q})-K\right] .
$$

Analogously to above, $\bar{X}$ corresponds to the manufacturer's additional profit when delivering to the $n-m$ retailers initially assigned to the intermediary. Using $\bar{X}$, the upfront payment simplifies to:

$$
\bar{Z}=\beta(1-\alpha)(n-m) K-(1-\beta)(\bar{\Pi}(\bar{q})-\underline{\Pi})-(n-m) \Delta(\widetilde{q}, \bar{q})
$$

which is weakly positive for $\alpha \rightarrow 0, \beta \rightarrow 1$ and $K \geq \Delta(\widetilde{q}, \bar{q})$ and negative otherwise. Even in the case of a negative $\bar{Z}$, which indicates an upfront payment from the manufacturer to the intermediary, the intermediary still prefers delivering to its $n-m$ retailers and, thus, purchasing $\bar{Q}_{M}$ at the price $\bar{X}$ over simply pocketing $\bar{Z}$ if $\alpha \leq \bar{\alpha}:=(K-\Delta(\widetilde{q}, \bar{q})) / K<1$ and $K \geq \Delta(\widetilde{q}, \bar{q}) .{ }^{30}$

Using our results, the collusive equilibrium profits of $U$ and $M$ are given by:

$$
\bar{\pi}_{U}^{M D}(\bar{q})=\beta[\bar{\Pi}(\bar{q})-\underline{\Pi}+(1-\alpha)(n-m) K]+\underline{\Pi}-n K
$$

and

$$
\bar{\pi}_{M}^{M D}(\bar{q})=(1-\beta)[\bar{\Pi}(\bar{q})-\underline{\Pi}+(1-\alpha)(n-m) K] .
$$

The upstream and intermediate firms' collusive equilibrium profits correspond to their noncollusive profits as given in (33) and (34) plus the difference in the collusive and non-collusive

\footnotetext{
${ }^{30}$ Comparing the intermediary's profit on the equilibrium path, $\bar{\pi}_{M}^{M D}(\bar{q})$ (see 42 below), with the upfront payment, we get $\bar{\pi}_{M}^{M D}(\bar{q}) \geq-\bar{Z}$ for all $\alpha \leq \bar{\alpha}$. Note that the condition on $\alpha$ that we impose is the strictest possible. An intertemporal consideration would relax the condition on $\alpha$.
} 
industry profits, i.e. $\bar{\Pi}(\bar{q})-\underline{\Pi}$, weighted by each party's respective bargaining power.

In the following, we analyze the deviation strategies from the collusive equilibrium path. While the intermediary cannot deviate individually from collusion, ${ }^{31}$ the manufacturer could deviate with its $m$ downstream retailers by offering each of them a larger quantity and extracting the corresponding rents with the fixed fees. Moreover, the manufacturer and the intermediary could deviate jointly.

Individual deviation incentive by $U$. When deviating individually, the manufacturer offers each of its initially assigned $m$ retailers the deviant quantity $\widetilde{q}$ and extracts the corresponding downstream rents through the fixed fees $\widetilde{F} .^{32}$ Thus, the manufacturer's profit when deviating from the collusive equilibrium path without cheating the intermediary is given by (38) and can be simplified to:

$$
\widetilde{\widetilde{\pi}}_{U}^{M D}(\widetilde{q}, \bar{q})=\bar{\pi}_{U}^{M D}(\bar{q})+m \Delta(\widetilde{q}, \bar{q})
$$

where $\Delta(\widetilde{q}, \bar{q})$ indicates the additional profit of the manufacturer from deviating with any of its $m$ retailers. $\Delta(\widetilde{q}, \bar{q})$ also corresponds to the loss imposed on each of the retailers $D_{U 1}, \ldots, D_{U m}$. Note that the deviation profit in (43) differs from the upstream firm's deviation profit under integrated distribution (18) only in the number of retailers the manufacturer deviates with. The upstream firm has no incentive to deviate individually from perfect collusion if the following incentive constraint holds:

$$
\frac{1}{1-\delta} \bar{\pi}_{U}^{M D}\left(q^{\max }\right) \geq \widetilde{\widetilde{\pi}}_{U}^{M D}\left(\widetilde{q}, q^{\max }\right)+\frac{\delta}{1-\delta} \underline{\pi}_{U}^{M D}(\underline{q})
$$

From (44), we get that perfect collusion is sustainable for all: ${ }^{33}$

$$
\delta \geq \delta_{s e p}^{U}(m):=\frac{m \Delta\left(\widetilde{q}, q^{\max }\right)}{\beta\left(\bar{\Pi}^{\max }-\underline{\Pi}\right)+m \Delta\left(\widetilde{q}, q^{\max }\right)} .
$$

Due to the agreement on the conditional payment $\bar{X}$, which is made only if the intermediary actually buys the predetermined quantity $\bar{Q}_{M}$, the manufacturer's incentive to deviate individually from perfect collusion vanishes completely if the manufacturer delegates the deliveries to all retailers to the intermediary. Correspondingly, we have $\left.\delta_{s e p}^{U}(m)\right|_{m=0}=0$. However,

\footnotetext{
${ }^{31}$ The reason is that the quantity the intermediary can purchase from the manufacturer is fixed. That is, the intermediary cannot deviate with its own $n-m$ retailers $D_{M m+1}, \ldots, D_{M n}$ by increasing the quantity it offers to them. Likewise, it has no incentive to make competing offers $(\bar{q}, \bar{F}-\varepsilon)$ or $(\widetilde{q}, \widetilde{F})$ to the retailers initially assigned to the manufacturer and, thus, always sticks to the ex-ante determined distribution structure.

${ }^{32}$ Additionally, the manufacturer could have an incentive to offer the $n-m$ retailers initially assigned to the intermediary the quantity $\widetilde{q}-\bar{q}$ at the price $\widetilde{F}-\bar{F}$, while the intermediary still sells $\bar{q}$ to each of its retailers and, thus, pays $\bar{X}$ to the manufacturer. The additional profit of the upstream firm from this deviation possibility would be given by $(n-m)(\Delta(\widetilde{q}, \bar{q})-K)$. Due to our requirement of $K \geq \Delta(\widetilde{q}, \bar{q})$, however, this additional profit would be negative, preventing the manufacturer from secretly supplying $\widetilde{q}-\bar{q}$ to the retailers $D_{M m+1}, \ldots, D_{M n}$.

${ }^{33}$ The case of disintegrated distribution, i.e. $m=0$, combined with full take-it-or-leave-it power by the intermediary, i.e. $\beta=0$, is never an equilibrium and has to be ruled out in the analysis.
} 
the more retailers the manufacturer supplies directly the higher $\delta_{s e p}^{U}(m)$. In the limit, i.e. for $m \rightarrow n$, the manufacturer's deviation incentive is stronger than under integrated distribution, i.e. $\left.\delta_{\text {sep }}^{U}(m)\right|_{m \rightarrow n} \geq \delta^{I}$.

Lemma 3 For $\beta>0$, comparative statics show that $\delta_{\text {sep }}^{U}(m)$ is monotonically increasing in $m$.

Proof. See the Appendix.

Furthermore, we find that $\delta_{\text {sep }}^{U}$ is decreasing in the bargaining power of the manufacturer, i.e. $\beta$. If the intermediary has full take-it-or-leave-it power vis-à-vis the manufacturer, i.e. $\beta=0$, we get $\left.\delta_{s e p}^{U}\right|_{\beta=0}=1$. In this case, the manufacturer would always deviate separately. Note, however, that the manufacturer never makes use of the intermediary if $\beta=0$ since it would not obtain more than the non-collusive profit under integrated distribution. For this reason, we can focus on $\beta>0$. For $\beta=1$, in turn, we have $\left.\delta_{\text {sep }}^{U}\right|_{\beta=1}<\delta^{I}<1$.

Joint deviation by $U$ and $M$. Besides deviating individually, the manufacturer could also have an incentive to deviate jointly with the intermediary. Thereby, the two firms agree on a contract $\widehat{T}_{M}\left(\widehat{Z}, \widehat{X}, \widehat{Q}_{M}\right)$, with $\widehat{Q}_{M}=(n-m) \widetilde{q}>\bar{Q}_{M}$. The higher quantity enables the intermediary to deviate with its $n-m$ retailers by offering each of them a quantity $\widehat{q}_{M j}=\widetilde{q}>\bar{q}$ and a corresponding fixed fee $\widehat{F}_{M j}=\widetilde{F}$. Correspondingly, the intermediate firm's reduced profit from joint deviation is:

$$
\widehat{\pi}_{M}^{M D}(\widetilde{q}, \bar{q})=(n-m) P\left(\widetilde{q}, \bar{Q}_{-j}\right) \widetilde{q}-\widehat{Z}-\widehat{X}-(n-m) \alpha K
$$

Since all retailers will return to infinite Nash reversion in the subsequent periods whenever the manufacturer deviates jointly with the intermediary, the manufacturer also deviates with its $m$ retailers by offering them a contract $(\widetilde{q}, \widetilde{F})$. The reduced profit from deviation for the upstream firm $U$ is, thus, given by:

$$
\widehat{\pi}_{U}^{M D}(\widetilde{q}, \bar{q})=m\left(P\left(\widetilde{q}, \bar{Q}_{-j}\right)-c\right) \widetilde{q}-m K+\widehat{Z}+\widehat{X}-(n-m) c \widetilde{q} .
$$

Given $\widehat{X}$, the upstream firm and the intermediary agree on the upfront payment $\widehat{Z}$ in order to share their joint profit. The upfront payment refers to $\widehat{Z}=\beta \widehat{Z}_{U}+(1-\beta) \widehat{Z}_{M}$, with:

$$
\widehat{Z}_{U}=(n-m) P\left(\widetilde{q}, \bar{Q}_{-j}\right) \widetilde{q}-\widehat{X}-(n-m) \alpha K
$$

and

$$
\widehat{Z}_{M}=-\left[m\left(P\left(\bar{q}, \bar{Q}_{-j}\right)-c\right) \bar{q}-m K+\widehat{X}-(n-m) c \widetilde{q}\right]+\underline{\Pi}-n K .
$$

As the intermediary has no outside option, it accepts any contract offer by the manufacturer which ensures at least its participation constraint. The manufacturer, in turn, can deliver directly to all retailers when the negotiations fail, implying an outside option of $\underline{\Pi}-n K$ (see 
above). Not being able to observe the contracts closed between the manufacturer and its $m$ retailers and holding passive beliefs, the intermediary expects the manufacturer to make the collusive equilibrium offer $(\bar{q}, \bar{F})$ to any of its $m$ retailers.

Again, the conditional payment $\widehat{X}$ serves as a commitment device for the manufacturer not to cheat the intermediary by offering the $n-m$ retailers initially assigned to the intermediary a contract $(\widetilde{q}, \widetilde{F}-\varepsilon)$. Thus, $\widehat{X}$ has to make the manufacturer indifferent between $\widehat{\pi}_{U}^{M D}(\widetilde{q}, \bar{q})$ and:

$$
\widehat{\widehat{\pi}}_{U}^{M D}(\widetilde{q}, \bar{q})=m\left[\left(P\left(\widetilde{q}, \bar{Q}_{-j}\right)-c\right) \widetilde{q}-K\right]+\widehat{Z}+(n-m)\left[\left(P\left(\widetilde{q}, \bar{Q}_{-j}\right)-c\right) \widetilde{q}-K\right]
$$

resulting in:

$$
\widehat{X}=(n-m)\left(P\left(\widetilde{q}, \bar{Q}_{-j}\right) \widetilde{q}-K\right)
$$

Correspondingly, the upfront payment in the case of joint deviation simplifies to $\widehat{Z}=\bar{Z}+$ $\beta(n-m) \Delta(\widetilde{q}, \bar{q})$. Even if $\widehat{Z}$ is negative, the intermediary has no incentive to pocket $\widehat{Z}$ without delivering to the retailers. ${ }^{34}$ Using our results, the upstream firm's profit from joint deviation reduces to:

$$
\widehat{\pi}_{U}^{M D}(\widetilde{q}, \bar{q})=\bar{\pi}_{U}^{M D}(\bar{q})+[m+\beta(n-m)] \Delta(\widetilde{q}, \bar{q}),
$$

while the intermediate firm's deviation profit is given by:

$$
\widehat{\pi}_{M}^{M D}(\widetilde{q}, \bar{q})=\bar{\pi}_{M}^{M D}(\bar{q})+(1-\beta)(n-m) \Delta(\widetilde{q}, \bar{q}) .
$$

That is, both firms share the profit from deviating with the $n-m$ retailers supplied by the intermediary according to their exogenously given bargaining power. The manufacturer additionally earns $m \Delta(\widetilde{q}, \bar{q})$ due to the deviation with its own $m$ retailers.

Based on the deviation profits (52) and (53), we find that neither the upstream firm nor the intermediate firm has an incentive to deviate jointly from the perfectly collusive equilibrium path if the following incentive constraints hold:

$$
\frac{1}{1-\delta} \bar{\pi}_{U}^{M D}\left(q^{\max }\right) \geq \widehat{\pi}_{U}^{M D}\left(\widetilde{q}, q^{\max }\right)+\frac{\delta}{1-\delta} \underline{\pi}_{U}^{M D}(\underline{q})
$$

and

$$
\frac{1}{1-\delta} \bar{\pi}_{M}^{M D}\left(q^{\max }\right) \geq \widehat{\pi}_{M}^{M D}\left(\widetilde{q}, q^{\max }\right)+\frac{\delta}{1-\delta} \underline{\pi}_{M}^{M D}(\underline{q})
$$

Using our results and reformulating (54) and (55), respectively, we obtain the corresponding

\footnotetext{
${ }^{34}$ Comparing the intermediary's deviation profit, $\widehat{\pi}_{M}^{M D}(\widetilde{q}, \bar{q})$ (see 53 below), with the upfront payment, we get $\widehat{\pi}_{M}^{M D}(\widetilde{q}, \bar{q}) \geq-\widehat{Z} \Leftrightarrow \bar{\pi}_{M}^{M D}(\bar{q})+(n-m) \Delta(\widetilde{q}, \bar{q}) \geq-\bar{Z}$, which is always fulfilled since $\bar{\pi}_{M}^{M D}(\bar{q}) \geq-\bar{Z}$ under our above assumptions.
} 
critical discount factor for the upstream firm by: ${ }^{35}$

$$
\delta_{\text {joint }}^{U}(m):=\frac{[m+\beta(n-m)] \Delta\left(\widetilde{q}, q^{\max }\right)}{\beta\left(\bar{\Pi}^{\max }-\underline{\Pi}\right)+[m+\beta(n-m)] \Delta\left(\widetilde{q}, q^{\max }\right)},
$$

while the critical discount factor for the intermediary for any $\beta<1$ is given by:

$$
\delta_{\text {joint }}^{M}(m):=\frac{(n-m) \Delta\left(\widetilde{q}, q^{\max }\right)}{\bar{\Pi}^{\max }-\underline{\Pi}+(n-m) \Delta\left(\widetilde{q}, q^{\max }\right)} .
$$

The manufacturer and the intermediary deviate jointly from the collusive equilibrium path only if both have an incentive to do so. For this reason, joint deviation only takes place for all $\delta<\min \left\{\delta_{\text {joint }}^{U}(m), \delta_{\text {joint }}^{M}(m)\right\}$. If the manufacturer has full take-it-or-leave-it power, i.e. $\beta=1$, the intermediary always gets zero profit, i.e. $\left.\widehat{\pi}_{M}^{M D}(\cdot)\right|_{\beta=1}=\left.\bar{\pi}_{M}^{M D}(\cdot)\right|_{\beta=1}=\left.\underline{\pi}_{M}^{M D}(\cdot)\right|_{\beta=1}=0$. In this case, the intermediary is indifferent between deviating together with the manufacturer or not. This implies that the manufacturer's incentive constraint is binding, such that the firms deviate jointly for all $\delta<\left.\delta_{\text {joint }}^{U}(m)\right|_{\beta=1}=\delta^{I}$. In turn, the intermediary's incentive constraint is binding if the intermediary has at least some bargaining power vis-à-vis the manufacturer, i.e. $\delta_{\text {joint }}^{M}(m) \leq \delta_{\text {joint }}^{U}(m)$ for all $\beta<1$.

Lemma 4 Given $\beta<1$, it holds that $\delta_{\text {joint }}^{M}(m) \leq \delta_{\text {joint }}^{U}(m)$. For $m=0$ and $\beta<1$, we find $\left.\delta_{\text {joint }}^{M}(m)\right|_{m=0}=\delta^{I}$. For any $m>0$ and $\beta<1$, we get $\delta_{\text {joint }}^{M}(m)<\delta^{I}$ since $\delta_{\text {joint }}^{M}(m)$ is monotonically decreasing in $m$.

Proof. See the Appendix.

Sustainability of collusion. For $\beta \in(0,1)$, we find that perfect collusion is sustainable for all $\delta \geq \max \left\{\delta_{\text {sep }}^{U}(m), \delta_{\text {joint }}^{M}(m)\right\}$. For $m=0$, the manufacturer has no individual deviation incentive due to the agreement on the conditional payment $\bar{X}$. The intermediary, however, has the strongest incentive to deviate jointly with the manufacturer if it supplies all retailers. Correspondingly, we have $\left.\delta_{\text {sep }}^{U}(m)\right|_{m=0}=0<\left.\delta_{\text {joint }}^{M}(m)\right|_{m=0}=\delta^{I}$. As $\delta_{\text {joint }}^{M}(m)$ is monotonically decreasing in $m$ (cf. Lemma 4 ) and $\delta_{\text {sep }}^{U}(m)$ is monotonically increasing in $m$ (cf. Lemma 3 ), the manufacturer is able to increase the sustainability of perfect collusion by directly delivering to some retailers itself. Thereby, the maximum number of retailers $\overline{\bar{m}}^{M D}$ to be directly supplied by the manufacturer is implicitly determined by $\delta_{\text {sep }}^{U}\left(\overline{\bar{m}}^{M D}\right) \equiv \delta_{\text {joint }}^{M}\left(\overline{\bar{m}}^{M D}\right):=\delta^{M D}$, resulting in $\overline{\bar{m}}^{M D}=\beta n /(1+\beta){ }^{36}$

For any $\delta \in\left[\delta^{M D}, \delta^{I}\right)$, we denote the optimal number of retailers to be directly supplied by the manufacturer by $\bar{m}^{M D}$. While $\bar{m}^{M D}=\overline{\bar{m}}^{M D}$ for $\delta^{M D}, \bar{m}^{M D}$ in the interval $\left(\delta^{M D}, \delta^{I}\right)$ refers to the number of retailers assigned to the upstream firm which makes the intermediary's

\footnotetext{
${ }^{35}$ As above, the case of $m=0$ combined with $\beta=0$ has to be ruled out.

${ }^{36}$ For simplicity, we do not require $\overline{\bar{m}}^{M D}$ to be an integer value.
} 
incentive constraint (55) hold. Note that the manufacturer is not willing to supply more retailers than necessary to obtain perfect collusion as its profit under perfect collusion (see 41, evaluated at $\left.q^{\max }\right)$ is decreasing in $m$.

For all $\delta<\delta^{M D}$, in turn, the optimal number of retailers the manufacturer supplies directly is given by $\overline{\bar{m}}^{M D}$, ensuring the highest industry profit under imperfect collusion. The reason is that the intermediary's incentive constraint is more binding than the manufacturer's for $m<$ $\overline{\bar{m}}^{M D}$, i.e. $\delta_{\text {sep }}^{U}\left(m<\overline{\bar{m}}^{M D}\right)<\delta^{M D}<\delta_{\text {joint }}^{M}\left(m<\overline{\bar{m}}^{M D}\right)$, while the manufacturer's incentive constraint is more binding than the intermediary's for $m>\overline{\bar{m}}^{M D}$, i.e. $\delta_{\text {sep }}^{U}\left(m>\overline{\bar{m}}^{M D}\right)>$ $\delta^{M D}>\delta_{\text {joint }}^{M}\left(m>\overline{\bar{m}}^{M D}\right)$.

Note further that the upstream firm decides not to deliver directly to any retailer for $\delta \geq \delta^{I}$ since perfect collusion is sustained in any case and since the perfectly collusive profit of the upstream firm is maximized for $m=0$.

As a result, the optimal number of retailers directly supplied by the upstream firm whenever it makes use of the intermediary is given by:

$$
m^{M D}(\delta)= \begin{cases}0 & \text { if } \delta \geq \delta^{I} \\ \bar{m}^{M D} & \text { if } \delta \in\left[\delta^{M D}, \delta^{I}\right) \\ \overline{\bar{m}}^{M D} & \text { if } \delta<\delta^{M D}\end{cases}
$$

For all $\delta \geq \delta^{M D}$, perfect collusion can be sustained, while imperfect collusion is obtained for all $\delta<\delta^{M D}$. Correspondingly, the collusive equilibrium quantities are given by:

$$
\bar{q}^{M D}= \begin{cases}q^{\max } & \text { if } \delta \geq \delta^{M D} \\ \overline{\bar{q}}^{M D} & \text { if } \delta<\delta^{M D}\end{cases}
$$

where $\overline{\bar{q}}^{M D}<q^{\max }$ is implicitly determined by making the intermediary's incentive constraint for joint deviation hold with equality:

$$
\left.\left(\frac{1}{1-\delta} \bar{\pi}_{M}^{M D}\left(\overline{\bar{q}}^{M D}\right) \equiv \widehat{\pi}_{M}^{M D}\left(\widetilde{q}, \overline{\bar{q}}^{M D}\right)+\frac{\delta}{1-\delta} \underline{\pi}_{M}^{M D}(\underline{q})\right)\right|_{m=\overline{\bar{m}}^{M D}}
$$

Note that the intermediary's incentive constraint for $m=\overline{\bar{m}}^{M D}$ coincides with the corresponding incentive constraint for individual deviation by the upstream firm. Summarizing our results, we find:

Lemma 5 For any $\delta \geq \delta^{M D}, \beta \in(0,1), \alpha \leq \bar{\alpha}$ and $K \geq \Delta(\widetilde{q}, \bar{q})$, perfect collusion can be sustained under the choice of $m^{M D}(\delta)$, implying $\bar{\pi}_{U}^{M D}\left(q^{\max }\right)$. For any $\delta<\delta^{M D}, \beta \in(0,1), \alpha \leq$ $\bar{\alpha}$ and $K \geq \Delta(\widetilde{q}, \bar{q})$, in turn, only imperfect collusion is sustainable and results in $\bar{\pi}_{U}^{M D}\left(\overline{\bar{q}}^{M D}\right)$.

From Lemmas 1, 4 and 5, it further follows: 
Proposition 1 Given $\beta \in(0,1), \alpha \leq \bar{\alpha}$ and $K \geq \Delta(\widetilde{q}, \bar{q})$, perfect collusion is more likely to occur under mixed distribution $\left(m=m^{M D}(\delta)\right)$ than under integrated distribution $(m=n)$ or disintegrated distribution $(m=0)$.

The manufacturer's individual deviation incentive is decreasing in the number of retailers assigned to the intermediary. Its profit from individual deviation is, therefore, lower under mixed distribution than under integrated distribution. In addition, the intermediary - whose joint deviation incentive is more binding than the upstream firm's for any $\beta<1$-is the less willing to deviate jointly the lower the number of retailers it supplies. This implies that the mixed distribution system reduces the intermediary's profit from joint deviation as compared to disintegrated distribution. At the same time, the intermediary's joint-deviation incentive under mixed distribution is lower than the upstream firm's deviation incentive when it supplies all retailers directly. Correspondingly, the mixed distribution system facilitates vertical collusion, leading to higher prices in the downstream market than integrated or disintegrated distribution for all $\delta<\delta^{I}$.

\section{Decision about the Distribution System}

The upstream firm's decision to use an intermediary for the delivery to at least some retailers is driven by three effects. The choice of the mixed distribution system induces a strategic effect by reducing the upstream firm's commitment problem and, thus, increasing the sustainability of vertical collusion. In addition, the manufacturer may benefit from the intermediary's cost advantage in distributing to the retailers. However, the manufacturer has to share the larger pie with the intermediary.

For $\delta \geq \delta^{I}$, perfect collusion is sustainable for any distribution system. Absent any strategic effect, the manufacturer benefits from making use of the intermediary only if $M$ 's cost advantage in delivering to the retailers is sufficiently high. Precisely, we find that the upstream firm chooses disintegrated distribution $\left(m^{*}=0\right)^{37}$ if $\left.\bar{\pi}_{U}^{M D}\left(q^{\max }\right)\right|_{m=0} \geq \bar{\pi}_{U}^{I}\left(q^{\max }\right)$, i.e. for all:

$$
\alpha \leq \underline{\alpha}:=1-\frac{(1-\beta)\left(\bar{\Pi}^{\max }-\underline{\Pi}\right)}{\beta n K} .
$$

Since $\underline{\alpha}$ is increasing in $\beta$, the intermediary's cost advantage necessary to make the use of the intermediary profitable for the manufacturer is decreasing in the manufacturer's bargaining power. Furthermore, we have that the threshold $\underline{\alpha}$ is not binding, i.e. $\underline{\alpha} \geq \bar{\alpha}$, for all $\beta \geq$ $\left(\bar{\Pi}^{\max }-\underline{\Pi}\right) /\left(\bar{\Pi}^{\max }-\underline{\Pi}+n \Delta\left(\widetilde{q}, q^{\max }\right)\right)$.

For $\delta<\delta^{I}$, only imperfect collusion can be sustained under integrated distribution. If, instead, the manufacturer uses the intermediary for the delivery to $n-m^{M D}(\delta)$ retailers, perfect

\footnotetext{
${ }^{37}$ Remember that $m^{M D}(\delta)=0$ for $\delta \geq \delta^{I}$ (see 58$)$.
} 
collusion can be sustained in the interval $\left[\delta^{M D}, \delta^{I}\right)$. Correspondingly, we find that the manufacturer has an incentive to choose mixed distribution $\left(m^{*}=\bar{m}^{M D}\right)$ as long as $\left.\bar{\pi}_{U}^{M D}\left(q^{\max }\right)\right|_{m=\bar{m}^{M D}} \geq$ $\bar{\pi}_{U}^{I}\left(\overline{\bar{q}}^{I}\right)$. This is the case if the intermediary's competitive advantage is sufficiently large: ${ }^{38}$

$$
\alpha \leq \overline{\bar{\alpha}}:=1-\frac{\bar{\Pi}\left(\overline{\bar{q}}^{I}\right)-\underline{\Pi}-\beta\left(\bar{\Pi}^{\max }-\underline{\Pi}\right)}{\beta\left(n-\bar{m}^{M D}\right) K} .
$$

Again, $\overline{\bar{\alpha}}$ is increasing in the manufacturer's bargaining power. We find that $\overline{\bar{\alpha}}$ places no restriction on the manufacturer's preference for the mixed distribution system, i.e. $\overline{\bar{\alpha}} \geq \bar{\alpha}$, as long as the manufacturer's bargaining power vis-à-vis the intermediary is sufficiently high, i.e. for all $\beta \geq\left(\bar{\Pi}\left(\overline{\bar{q}}^{I}\right)-\underline{\Pi}\right) /\left(\bar{\Pi}^{\max }-\underline{\Pi}+\left(n-\bar{m}^{M D}\right) \Delta\left(\widetilde{q}, q^{\max }\right)\right)$.

For $\delta<\delta^{M D}$, perfect collusion cannot be sustained in any distribution system. When making use of the intermediary, the manufacturer will always set $\overline{\bar{m}}^{M D}$ in order to increase the industry profit under imperfect collusion (see above). Comparing $\left.\bar{\pi}_{U}^{M D}\left(\overline{\bar{q}}^{M D}\right)\right|_{m=\overline{\bar{m}}^{M D}}$ and $\bar{\pi}_{U}^{I}\left(\overline{\bar{q}}^{I}\right)$, we find that the upstream firm prefers mixed distribution if: ${ }^{39}$

$$
\alpha \leq \underline{\underline{\alpha}}:=1-\frac{\bar{\Pi}\left(\overline{\bar{q}}^{I}\right)-\underline{\Pi}-\beta\left(\bar{\Pi}\left(\overline{\bar{q}}^{M D}\right)-\underline{\Pi}\right)}{\beta\left(n-\overline{\bar{m}}^{M D}\right) K} .
$$

As above, it holds that $\underline{\alpha} \geq \bar{\alpha}$ if the manufacturer's bargaining power is sufficiently high, i.e. for all $\beta \geq\left(\bar{\Pi}\left(\overline{\bar{q}}^{I}\right)-\underline{\Pi}\right) /\left(\overline{\bar{\Pi}}\left(\overline{\bar{q}}^{M D}\right)-\underline{\Pi}+\left(n-\overline{\bar{m}}^{M D}\right) \Delta\left(\widetilde{q}, \overline{\bar{q}}^{M D}\right)\right) \cdot{ }^{40}$

Summarizing our results, we get:

Proposition 2 For $\beta \in(0,1), \alpha \leq \bar{\alpha}$ and $K \geq \Delta(\widetilde{q}, \bar{q})$, the manufacturer's equilibrium choice of the distribution system is given by:

$$
m^{*}=\left\{\begin{array}{ll}
0 & \text { if } \delta \geq \delta^{I} \text { and } \alpha \leq \underline{\alpha} \\
n & \text { if } \delta \geq \delta^{I} \text { and } \alpha>\underline{\alpha} \\
\bar{m}^{M D} & \text { if } \delta \in\left[\delta^{M D}, \delta^{I}\right) \text { and } \alpha \leq \overline{\bar{\alpha}} \\
n & \text { if } \delta \in\left[\delta^{M D}, \delta^{I}\right) \text { and } \alpha>\overline{\bar{\alpha}} \\
\overline{\bar{m}}^{M D} & \text { if } \delta<\delta^{M D} \text { and } \alpha \leq \underline{\underline{\alpha}} \\
n & \text { if } \delta<\delta^{M D} \text { and } \alpha>\underline{\underline{\alpha}}
\end{array} .\right.
$$

We illustrate our results in Figures $2 \mathrm{a}$ and $2 \mathrm{~b}$ for varying degrees of the upstream firm's bargaining power. Thereby, we apply a system of linear inverse demand functions $P\left(q_{i j}, Q_{-j}\right)=$

\footnotetext{
${ }^{38}$ Note that $\overline{\bar{\alpha}}>0$ if $K>\bar{K}:=\left[\bar{\Pi}\left(\overline{\bar{q}}^{I}\right)-\underline{\Pi}-\beta\left(\bar{\Pi}^{\max }-\underline{\Pi}\right)\right] / \beta\left(n-\bar{m}^{M D}\right)$, which is only binding for $\bar{K}>0$, i.e. for $\beta<\underline{\beta}:=\left(\bar{\Pi}\left(\overline{\bar{q}}^{I}\right)-\underline{\Pi}\right) /\left(\bar{\Pi}^{\max }-\underline{\Pi}\right)$.

${ }^{39}$ It holds that $\underline{\underline{\alpha}}>0$ if $K>\overline{\bar{K}}:=(1+\beta)\left[\bar{\Pi}\left(\overline{\bar{q}}^{I}\right)-\underline{\Pi}-\beta\left(\bar{\Pi}\left(\overline{\bar{q}}^{M D}\right)-\underline{\Pi}\right)\right] / \beta n$, which is only binding for $\overline{\bar{K}}>0$, i.e. for $\beta<\underline{\beta}:=\left(\bar{\Pi}\left(\overline{\bar{q}}^{I}\right)-\underline{\Pi}\right) /\left(\bar{\Pi}\left(\overline{\bar{q}}^{M D}\right)-\underline{\Pi}\right)$, where we always have $\underline{\beta}<1$ due to $\bar{\Pi}\left(\overline{\bar{q}}^{M D}\right)>\bar{\Pi}\left(\overline{\bar{q}}^{I}\right)$. ${ }^{40}$ Since $\bar{\Pi}\left(\overline{\bar{q}}^{M D}\right)>\bar{\Pi}\left(\overline{\bar{q}}^{I}\right)$, we have $\left(\bar{\Pi}\left(\overline{\bar{q}}^{I}\right)-\underline{\Pi}\right) /\left(\bar{\Pi}\left(\overline{\bar{q}}^{M D}\right)-\underline{\Pi}+\left(n-\overline{\bar{m}}^{M D} \overline{\overline{\bar{D}}}\right) \Delta\left(\widetilde{q}, \overline{\bar{q}}^{M D}\right)\right)<1$.
} 


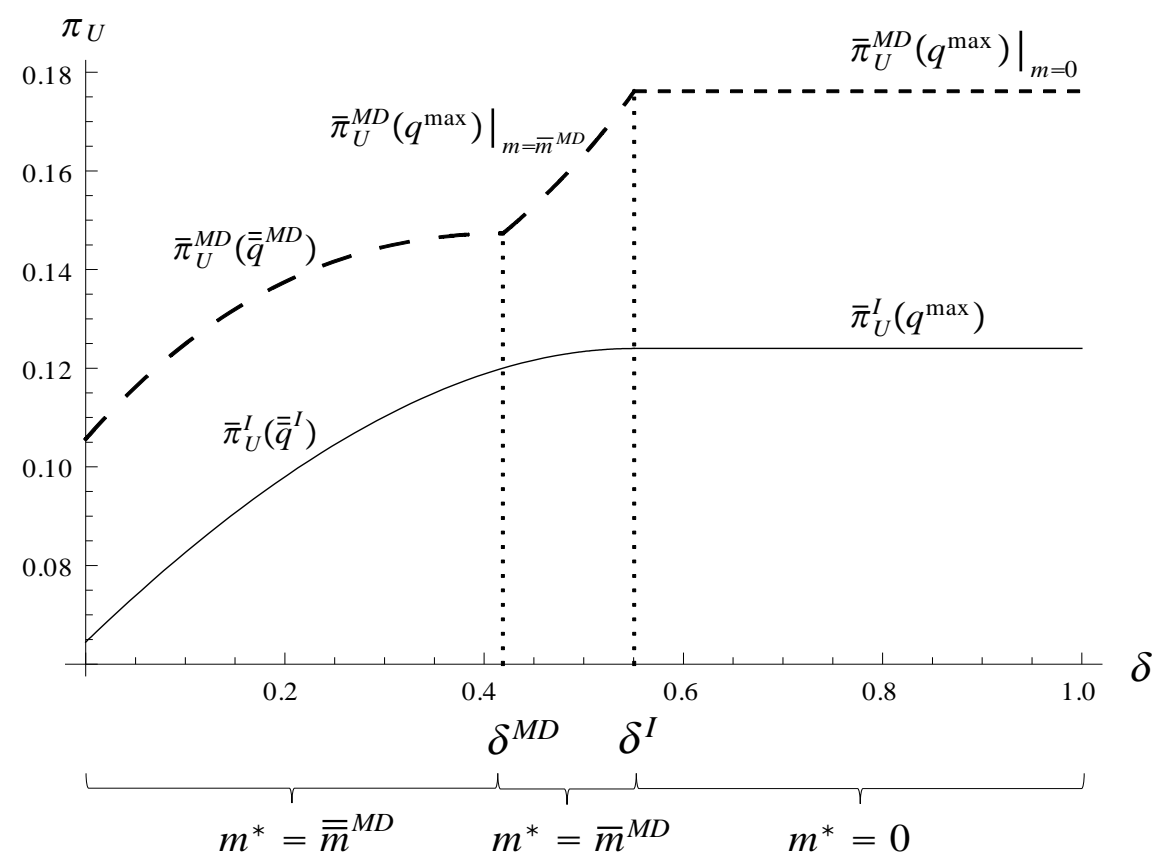

Figure 2a: U's Profits and Choice of $m^{*}$ for $\beta=0.7$

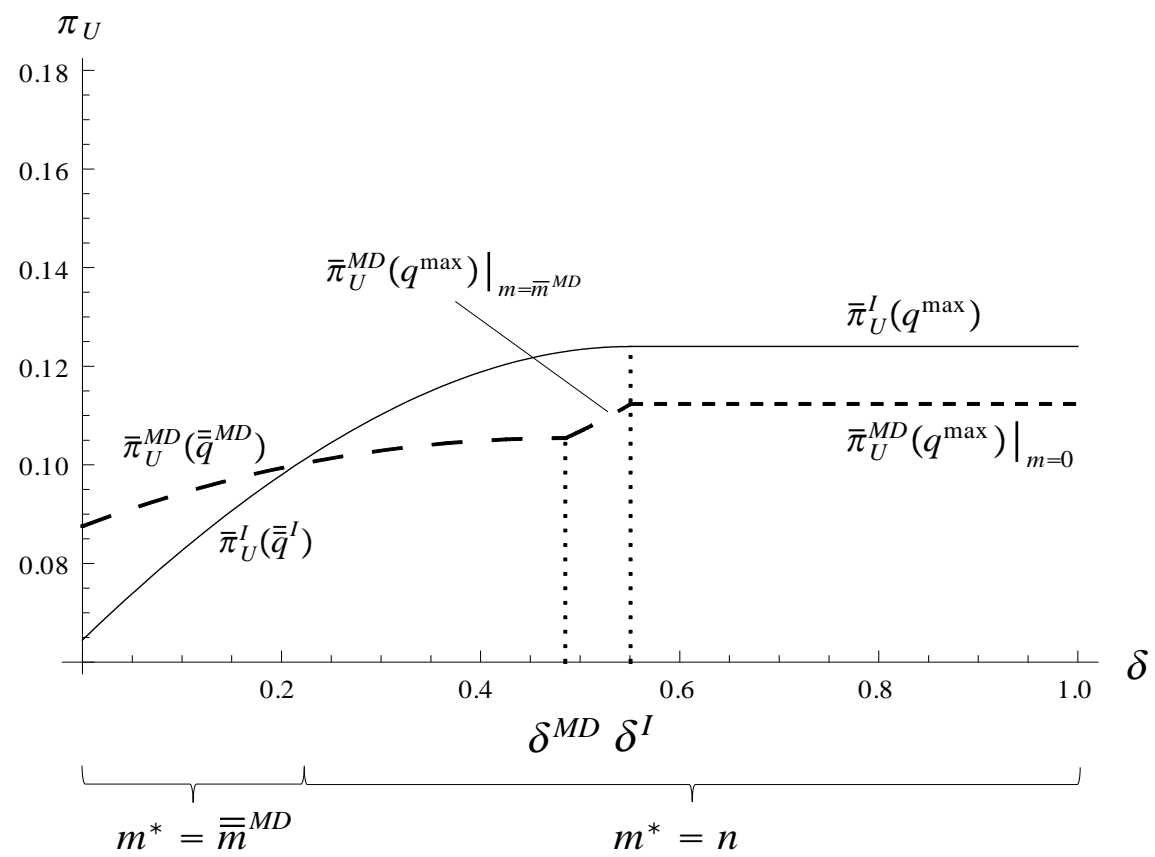

Figure 2b: U's Profits and Choice of $m^{*}$ for $\beta=0.3$ 
$1-q_{i j}-\sigma Q_{-j}$, where the parameter $\sigma \in(0,1)$ indicates the degree of substitutability between the goods offered by the retailers. The goods are the more substitutable the higher $\sigma{ }^{41}$ Furthermore, we set $\alpha=0.5$ so as to fulfill the condition $\alpha \leq \bar{\alpha}$ and $K=0.05$ to satisfy $\Delta\left(\widetilde{q}, q^{\max }\right) \leq K<$ $\underline{\Pi} / n{ }^{42}$ The remaining parameters are given by $\sigma=0.5, n=4$, and $c=0.1$.

The figures show that $\delta^{M D}$ decreases in $\beta$. Correspondingly, the manufacturer is the more likely to choose the mixed distribution system the higher its bargaining power vis-à-vis the manufacturer. More precisely, for $\beta=0.7$, the upstream firm opts for mixed distribution in the entire range of $\delta \in\left[0, \delta^{I}\right.$ ) and chooses disintegrated distribution for all $\delta \geq \delta^{I}$ (Figure 2a). For $\beta=0.3$, in turn, the range of discount factors for which the upstream firm implements the mixed distribution system is drastically reduced to very low $\delta$ and integrated distribution becomes the preferred choice for all remaining $\delta$ (Figure 2b). Note that, due to $\alpha<1$, the manufacturer always chooses the mixed distribution system for $\delta=0$, i.e. when earning the non-collusive profit (cf. Lemma 2).

\section{Conclusion}

We provide a new rationale for the use of intermediaries, such as wholesalers and distributors, in value chains. In an infinitely repeated game with secret contracts, we show that an upstream monopolist can restore its market power when supplying some downstream firms directly and others indirectly via an intermediary. That is, vertical collusion is more likely to be sustained if the upstream firm implements a mixed distribution system.

The reason is that the upstream firm's incentive to deviate from the collusive equilibrium path is reduced if it is committed to sell to a fewer number of retailers. At the same time, the intermediary's incentive to deviate jointly with the upstream firm is both lower than the upstream firm's deviation incentive when supplying all retailers directly and the intermediary's joint-deviation incentive when all retailers are supplied indirectly. This result holds as long as the intermediary has at least some bargaining power vis-à-vis the manufacturer and if both the intermediary's cost advantage in distribution and the delivery costs are sufficiently high.

The manufacturer makes use of the intermediary whenever the associated increase in the industry profit exceeds the reduction in the upstream firm's share of the pie due to the profitsharing with the intermediary. Thereby, the upstream firm is the more likely to choose the mixed distribution system the more efficient the intermediary, the higher the upstream firm's bargaining power, and the lower the discount factor. Thus, our results reveal that a split of the

\footnotetext{
${ }^{41}$ Note that for $\sigma=0$, i.e. when the markets are separated, the commitment problem would not exist and full collusion could be always sustained.

${ }^{42}$ Note that $K \geq \Delta\left(\widetilde{q}, q^{\max }\right)$ is the strictest condition among all $K \geq \Delta(\widetilde{q}, \bar{q})$. The upper bound on $K$ results from the upstream firm's participation constraint in the non-collusive equilibrium under integrated distribution (see above).
} 
delivery to the retailers can have strong anti-competitive effects by inducing higher prices in the downstream market. In other words, the use of a more efficient intermediary can be detrimental to welfare.

Finally, our analysis also points out that there can be substantial differences between two-tier and three-tier industry structures. However, the literature on vertical relations tends to ignore the various stages of production processes by commonly representing the value chains as simple two-tier structures with upstream sellers and downstream buyers. ${ }^{43}$ While this simplification is valid for many settings, our findings reveal that the results derived from two-tier structures cannot always be transferred to the multi-tier value chains that are observed in reality.

\section{References}

[1] Baake, P., Kamecke, U., Normann, H.-T., 2004. Vertical foreclosure versus downstream competition with capital precommitment. International Journal of Industrial Organization 22(2), 185-192.

[2] Berto Villas-Boas, S., 2007. Vertical relationships between manufacturers and retailers: inference with limited data. Review of Economic Studies 74(2), 625-652.

[3] Binmore, K., Rubinstein, A., Wolinsky, A., 1986. The Nash bargaining solution in economic modelling. RAND Journal of Economics 17(2), 176-188.

[4] Bonanno, G., Vickers, J., 1988. Vertical separation. Journal of Industrial Economics 36(3), 257-265.

[5] Bonnet, C., Dubois, P., 2010. Inference on vertical contracts between manufacturers and retailers allowing for nonlinear pricing and resale price maintenance. RAND Journal of Economics 41(1), 139-164.

[6] Chiang, W. K., Chhajed, D., Hess, J. D., 2003. Direct marketing, indirect profits: a strategic analysis of dual-channel supply-chain design. Management Science 49(1), 1-20.

[7] DeGraba, P., 1996. Most-favored-customer clauses and multilateral contracting: when nondiscrimination implies uniformity. Journal of Economics 8 Management Strategy 5(4), 565-579.

[8] DeGraba, P., Postlewaite, A., 1992. Exclusivity clauses and best price policies in input markets. Journal of Economics \&s Management Strategy 1(3), 423-454.

\footnotetext{
${ }^{43}$ See Inderst (2010) and Rey and Vergé (2008) for detailed surveys on the literature on vertical relations.
} 
[9] Friedman, J. W., 1971. A non-cooperative equilibrium for supergames. Review of Economic Studies 38(1), 1-12.

[10] Hardt, M., 1995. Market foreclosure without vertical integration. Economics Letters 47(34), 423-429.

[11] Hart, O., Tirole, J., 1990. Vertical integration and market foreclosure. Brookings Papers on Economic Activity. Microeconomics, 205-286.

[12] Hsiao, L., Chen, Y.-J., 2014. Strategic motive for introducing internet channels in a supply chain. Production and Operations Management 23(1), 36-47.

[13] Inderst, R., 2010. Models of vertical market relations. International Journal of Industrial Organization 28(4), 341-344.

[14] Inderst, R., Shaffer, G., 2007. Retail Mergers, Buyer Power and Product Variety. Economic Journal 117, 45-67.

[15] Jullien, B., Rey, P., 2007. Resale price maintenance and collusion. RAND Journal of Economics 38(4), 983-1001.

[16] Marx, L. M., Shaffer, G., 2004. Opportunism in multilateral vertical contracting: nondiscrimination, exclusivity and uniformity: comment. American Economic Review 94(3), 796801.

[17] Marx, L. M., Shaffer, G., 2007. Upfront payments and exclusion in downstream markets. RAND Journal of Economics 38(3), 823-843.

[18] McAfee, R. P., Schwartz, M., 1995. The non-existence of pairwise-proof equilibrium. Economics Letters 49(3), 251-259.

[19] McAfee, R. P., Schwartz, M., 1994. Opportunism in multilateral vertical contracting: nondiscrimination, exclusivity, and uniformity. American Economic Review 84(1), 210-230.

[20] Miklós-Thal, J., Rey, P., Vergé, T., 2011. Buyer power and intrabrand coordination. Journal of the European Economic Association 9(4), 721-741.

[21] Montez, J., 2014. Controlling opportunism in vertical contracting when production precedes sales. RAND Journal of Economics, forthcoming.

[22] Nocke, V., White, L., 2007. Do vertical mergers facilitate upstream collusion? American Economic Review 97(4), 1321-1339.

[23] Nocke, V., White, L., 2010. Vertical merger, collusion, and disruptive buyers. International Journal of Industrial Organization 28(4), 350-354. 
[24] Normann, H.-T., 2009. Vertical integration, raising rivals' costs and upstream collusion. European Economic Review 53(4), 461-480.

[25] O'Brien, D. P., Shaffer, G., 1992. Vertical control with bilateral contracts. RAND Journal of Economics 23(3), 299-308.

[26] Piccolo, S., Miklós-Thal, J., 2012. Colluding through suppliers. RAND Journal of Economics 43(3), 492-513.

[27] Piccolo, S., Reisinger, M., 2011. Exclusive territories and manufacturers' collusion. Management Science 57(7), 1250-1266.

[28] Ragan, V. K., Jaikumar, R., 1991. Integrating distribution strategy and tactics: a model and an application. Management Science 37(11), 1377-1389.

[29] Rey, P., Stiglitz, J., 1988. Vertical restraints and producers' competition. European Economic Review 32(2-3), 561-568.

[30] Rey, P., Stiglitz, J., 1995. The role of exclusive territories in producers' competition. RAND Journal of Economics 26(3), 431-451.

[31] Rey, P., Tirole, J., 2007. A primer on foreclosure, in: Armstrong, M., Porter, R. (eds.), Handbook of Industrial Organization Vol. 3, 2145-2220.

[32] Rey, P., Vergé, T., 2004. Bilateral control with vertical contracts. RAND Journal of Economics 35(4), 728-746.

[33] Rey, P., Vergé, T., 2008. Economics of vertical restraints, in: Buccirossi, P. (ed.), Handbook of Antitrust Economics, MIT Press, 353-390.

[34] Rosenbloom, B., 2013. Marketing channels: a management view. South-Western, Cengage Learning, Eighth International Edition.

[35] Schinkel, M. P., Tuinstra, J., Rüggeberg, J., 2008. Illinois Walls: how barring indirect purchaser suits facilitates collusion. RAND Journal of Economics 39(3), 683-698.

[36] Tirole, J., 1988. The theory of industrial organization. Massechussetts Institute of Technology.

[37] Tsay, A. A., Agrawal, N., 2004. Channel conflict and coordination in the e-commerce age. Production and Operations Management 13(1), 93-110.

[38] Vickers, J., 1985. Delegation and the theory of the firm. The Economic Journal 95, 138-147. 


\section{Appendix}

Proof of Lemma 1. To proof that $\overline{\bar{q}}^{I}$ is decreasing in $\delta$, we rewrite (21) to get:

$$
\Phi\left(\overline{\bar{q}}^{I}\right)=\bar{\pi}_{U}^{I}\left(\overline{\bar{q}}^{I}\right)-(1-\delta) \widetilde{\pi}_{U}^{I}\left(\widetilde{q}, \overline{\bar{q}}^{I}\right)-\delta \underline{\pi}_{U}^{I}(\underline{q})=0
$$

Applying the implicit-function theorem, we obtain:

$$
\frac{\partial \overline{\bar{q}}^{I}}{\partial \delta}=-\frac{\partial \Phi\left(\overline{\bar{q}}^{I}\right) / \partial \delta}{\partial \Phi\left(\overline{\bar{q}}^{I}\right) / \partial \overline{\bar{q}}^{I}}
$$

We find that $\partial \Phi\left(\overline{\bar{q}}^{I}\right) / \partial \delta>0$ since $\widetilde{\pi}_{U}^{I}\left(\widetilde{q}, \overline{\bar{q}}^{I}\right)>\underline{\pi}_{U}^{I}(\underline{q})$. Moreover, we can rewrite (65) by using (18) as:

$$
\Phi\left(\overline{\bar{q}}^{I}\right)=\delta \bar{\pi}_{U}^{I}\left(\overline{\bar{q}}^{I}\right)-(1-\delta) n \Delta\left(\widetilde{q}, \overline{\bar{q}}^{I}\right)-\delta \underline{\pi}_{U}^{I}(\underline{q}) .
$$

We, thus, get:

$$
\frac{\partial \Phi\left(\overline{\bar{q}}^{I}\right)}{\partial \overline{\bar{q}}^{I}}=\delta \frac{\partial \bar{\pi}_{U}^{I}\left(\overline{\bar{q}}^{I}\right)}{\partial \overline{\bar{q}}^{I}}-(1-\delta) n\left[\frac{\partial \Delta\left(\widetilde{q}, \overline{\bar{q}}^{I}\right)}{\partial \overline{\bar{q}}^{I}}+\frac{\partial \Delta\left(\widetilde{q}, \overline{\bar{q}}^{I}\right)}{\partial \widetilde{q}} \frac{\partial \widetilde{q}}{\partial \overline{\bar{q}}^{I}}\right]
$$

Using (16) and $\bar{Q}_{-j}^{e}=\bar{Q}_{-j}$, (68) simplifies to:

$$
\frac{\partial \Phi\left(\overline{\bar{q}}^{I}\right)}{\partial \overline{\bar{q}}^{I}}=\left.n\left(P\left(q_{U j}, \bar{Q}_{-j}^{e}\right)-c+\frac{\partial P\left(q_{U j}, \bar{Q}_{-j}^{e}\right)}{\partial q_{U j}} q_{U j}\right)\right|_{q_{U j}=\overline{\bar{q}}^{I}}>0
$$

since $\overline{\bar{q}}^{I}<\widetilde{q}$.

Proof of Lemma 3. Denoting $Q_{-j}^{\max }:=(n-1) q^{\max }, \delta_{\text {sep }}^{U}(m)$ can be written as:

$$
\delta_{s e p}^{U}(m)=\frac{m\left(P\left(\widetilde{q}, Q_{-j}^{\max }\right)-c\right) \widetilde{q}-m\left(P\left(q^{\max }, Q_{-j}^{\max }\right)-c\right) q^{\max }}{\beta\left(\bar{\Pi}^{\max }-\underline{\Pi}\right)+m\left(P\left(\widetilde{q}, Q_{-j}^{\max }\right)-c\right) \widetilde{q}-m\left(P\left(q^{\max }, Q_{-j}^{\max }\right)-c\right) q^{\max }} .
$$

Taking the derivative of $\delta_{\text {sep }}^{U}(m)$ with respect to $m$, we get:

$$
\frac{\partial \delta_{s e p}^{U}(m)}{\partial m}=\frac{\left[\left(P\left(\widetilde{q}, Q_{-j}^{\max }\right)-c\right) \widetilde{q}-\left(P\left(q^{\max }, Q_{-j}^{\max }\right)-c\right) q^{\max }\right] \beta\left(\bar{\Pi}^{\max }-\underline{\Pi}\right)}{\left[\beta\left(\bar{\Pi}^{\max }-\underline{\Pi}\right)+m\left(P\left(\widetilde{q}, Q_{-j}^{\max }\right)-c\right) \widetilde{q}-m\left(P\left(q^{\max }, Q_{-j}^{\max }\right)-c\right) q^{\max }\right]^{2}}
$$

For $\beta>0$, we have $\partial \delta_{\text {sep }}^{U}(m) / \partial m>0$ since $\left(P\left(\widetilde{q}, Q_{-j}^{\max }\right)-c\right) \widetilde{q}-\left(P\left(q^{\max }, Q_{-j}^{\max }\right)-c\right) q^{\max }>$ 0 and $\bar{\Pi}^{\max }-\underline{\Pi}>0$.

Proof of Lemma 4. To proof that $\delta_{\text {joint }}^{M}(m)$ is monotonically decreasing in $m$, we take the 
derivative of $\delta_{\text {joint }}^{M}(m)$ with respect to $m$ :

$$
\frac{\partial \delta_{\text {joint }}^{M}}{\partial m}=\frac{-\left[\left(P\left(\widetilde{q}, Q_{-j}^{\max }\right)-c\right) \widetilde{q}-\left(P\left(q^{\max }, Q_{-j}^{\max }\right)-c\right) q^{\max }\right]\left(\bar{\Pi}^{\max }-\underline{\Pi}\right)}{\left[\bar{\Pi}^{\max }-\underline{\Pi}+(n-m)\left[\left(P\left(\widetilde{q}, Q_{-j}^{\max }\right)-c\right) \widetilde{q}-\left(P\left(q^{\max }, Q_{-j}^{\max }\right)-c\right) q^{\max }\right]\right]^{2}} .
$$

It follows that $\partial \delta_{\text {joint }}^{M}(m) / \partial m<0$ since $\left(P\left(\widetilde{q}, Q_{-j}^{\max }\right)-c\right) \widetilde{q}-\left(P\left(q^{\max }, Q_{-j}^{\max }\right)-c\right) q^{\max }>0$ and $\bar{\Pi}^{\max }-\underline{\Pi}>0$. 